\title{
Molecular Mechanisms of Cytotoxicity and Apoptosis Induced by Inorganic Fluoride
}

\author{
Natalia Ivanovna Agalakova and Gennadii Petrovich Gusev \\ Sechenov Institute of Evolutionary Physiology and Biochemistry, Russian Academy of Sciences, 44 M. Thorez Avenue, \\ Sankt-Petersburg 194223, Russia \\ Correspondence should be addressed to Natalia Ivanovna Agalakova, nagalak@mail.ru
}

Received 28 November 2011; Accepted 21 December 2011

Academic Editors: Z. Pan and R. Poon

Copyright (๑) 2012 N. I. Agalakova and G. P. Gusev. This is an open access article distributed under the Creative Commons Attribution License, which permits unrestricted use, distribution, and reproduction in any medium, provided the original work is properly cited.

\begin{abstract}
Fluoride (F) is ubiquitous natural substance and widespread industrial pollutant. Although low fluoride concentrations are beneficial for normal tooth and bone development, acute or chronic exposure to high fluoride doses results in adverse health effects. The molecular mechanisms underlying fluoride toxicity are different by nature. Fluoride is able to stimulate G-proteins with subsequent activation of downstream signal transduction pathways such as PKA-, PKC-, PI3-kinase-, $\mathrm{Ca}^{2+}$-, and MAPK-dependent systems. G-protein-independent routes include tyrosine phosphorylation and protein phosphatase inhibition. Along with other toxic effects, fluoride was shown to induce oxidative stress leading to excessive generation of ROS, lipid peroxidation, decrease in the GSH/GSSH ratio, and alterations in activities of antioxidant enzymes, as well as to inhibit glycolysis thus causing the depletion of cellular ATP and disturbances in cellular metabolism. Fluoride triggers the disruption of mitochondria outer membrane and release of cytochrome $\mathrm{c}$ into cytosol, what activates caspases- 9 and -3 (intrinsic) apoptotic pathway. Extrinsic (death receptor) Fas/FasL-caspase- 8 and -3 pathway was also described to be implicated in fluoride-induced apoptosis. Fluoride decreases the ratio of antiapoptotic/proapoptotic Bcl-2 family proteins and upregulates the expression of p53 protein. Finally, fluoride changes the expression profile of apoptosis-related genes and causes endoplasmic reticulum stress leading to inhibition of protein synthesis.
\end{abstract}

\section{Introduction}

Fluorine (F), a member of the halogen family, is the most electronegative and reactive of all the elements of Periodic table. Elemental fluorine does not exist in nature but forms inorganic and organic compounds called fluorides representing approximately $0.06-0.09 \%$ of the Earth's crust. Fluorides are released into environment through a combination of natural and anthropogenic processes; therefore, their concentrations in the environment are highly variable. Natural processes include the weathering and dissolution of fluoriderich minerals, emissions from volcanoes, geothermal activity, and marine aerosols $[1,2]$. Fluoride levels in surface waters depend on geographical location and proximity to emission sources but are generally low, ranging from 0.01 to $0.3 \mathrm{mg} / \mathrm{L}$ in freshwater and from 1.2 to $1.5 \mathrm{mg} / \mathrm{L}$ in seawater. However, high fluoride concentrations ( $3 \mathrm{mg} / \mathrm{L}$ and greater) are common in the groundwaters at many geographical areas rich with fluoride-containing rocks. These regions include East African Rift system (from Jordan in northern Africa to Kenya and Tanzania in east Africa), Middle East (Iran, Iraq, and Syria), Indian subcontinent (India, Pakistan, SriLanka), parts of the USA, China, Argentina, and some regions of Central Europe [3-5]. Anthropogenic fluoride sources include the release of processed waters and waste from various industrial sites, including steel, aluminum, copper and nickel production, phosphate ore processing, phosphate fertilizer manufacturing and use, and glass, brick, and ceramic manufacturing $[3,4]$. Phosphate ore production and aluminum manufacture are the major industrial sources of environmental fluoride pollution. The use of fluoridecontaining pesticides and combustion of the coal and fuel also contribute to fluoride dispersion. These processes result in accumulation of fluoride compounds in the surface waters and groundwater reserves, air, soils, and in the living organisms. The most common inorganic fluorides are 
hydrogen fluoride (HF), calcium fluoride $\left(\mathrm{CaF}_{2}\right)$, sodium fluoride $(\mathrm{NaF})$, sulfur hexafluoride $\left(\mathrm{SF}_{6}\right)$, and silicofluorides.

Fluoride is consumed by an organism via inhalation of air and ingestion of food and water. The levels of fluoride in most fruits, vegetables, and meats are very low $(0.1-5 \mathrm{mg} / \mathrm{kg})$ and unlikely to contribute significantly to daily fluoride exposure, with exception of tea, containing relatively high fluoride levels especially in mature and fallen tea leaves [6]. Thus, the main source of fluoride for humans is drinking water. Fluoride in low concentrations has been proven to be beneficial for teeth and bone development; therefore, in the developed countries, the controlled fluoridation of drinking water supplies was introduced as early as in 40th years of the twentieth century $[3,4,7]$. Public health workers consider water fluoridation one of the greatest public health achievements of the twentieth century along with purification of drinking water, pasteurization of food products, and immunization against infectious diseases. Hence, although the toxicity of fluoride is well known, it has been ignored for a long time. According to WHO recommendations, the fluoride intake standard was set between 0.7 and $1.2 \mathrm{mg} / \mathrm{L}$ ( $1 \mathrm{ppm}$ in average). Taking into account the volume of consumed water, this gives an optimal daily uptake of fluoride by average adult (expressed on a body weight basis) of $1.4-3.4 \mathrm{mg} /$ day [8]. However, in the developed countries, a wide range of fluoride-containing topical agents and supplements (toothpastes, dental varnishes, gels, rinses, tablets, and drops) designed to reduce dental decay became widely available and greatly contribute to daily intake of fluoride by humans. As a result, the consumption of fluoride by humans became uncontrolled and unpredictable often exceeding its therapeutic window. An excessive fluoride consumption has been linked to development of fluorosis, a slow degenerative disease, affecting teeth and bone tissues, as well as inducing neurological defects, infertility, and mental retardation [8-12]. Endemic fluorosis is a serious national problem occurring in many counties all over the world and affecting many millions of people using groundwater with high fluoride content for their daily needs $[3,13]$. Moreover, there are no convincing evidences on the role of fluoride as essential element for normal human growth and development. In contrast, during recent decades, numerous investigations have established the toxicity of fluoride for cells of different tissues both in vitro and in vivo. The goal of present work was to summarize the literature data on the toxic effects of fluoride described to date with the focus on the molecular mechanisms underlying fluoride-induced cytotoxicity eventually leading to apoptotic cell death.

\section{Fluoride-Induced Toxicity and Cell Death}

The toxicity of fluoride is associated with its high chemical and biological activity. Fluoride freely and rapidly migrates across the biological membranes, primarily in the form of HF via passive nonionic diffusion in response to differences in the acidity of adjacent body fluid compartments [14]. The permeability coefficient of HF is more than one million times greater than that of ionic fluoride and close to water permeability [15]. After ingestion, fluoride is rapidly and virtually totally absorbed into the blood. The literature data present a quite different values (0.4$2.4 \mu \mathrm{mol} / \mathrm{L}$ ) for normal plasma fluoride content; however, the mean fluoride concentration in plasma from human individuals consuming drinking water with optimal fluoride amounts $(0.7-1.2 \mathrm{mg} / \mathrm{L})$ was established to be $1 \mu \mathrm{mol} / \mathrm{L}[4$, 16]. The concentrations of ionic fluoride in plasma of adults with endemic fluorosis elevate up to $30-80 \mu \mathrm{mol} / \mathrm{L}$, while those in the serum of patients survived after acute fluoride poisoning were estimated to be $500-780 \mu \mathrm{mol} / \mathrm{L}$ [16]. On an average, approximately $50 \%$ of the fluoride ingested by our body each day is excreted through the kidneys while the remaining fluoride distributes between organs and tissues and accumulates in the bones, teeth, pineal glands, and other tissues [14].

The effects of fluoride on cellular metabolism and physiology vary according to cell type, concentration, and time of exposure [17]. For instance, in teeth and bone tissues, micromolar concentrations of fluoride elicit potentially beneficial effects by promoting cell proliferation and growth, whereas millimolar fluoride doses suppress cell proliferation and induce apoptosis. Thus, an exposure to high fluoride doses has been reported to induce apoptotic cell death in ameloblasts [18-20], odontoblasts [21], and osteoblasts [2224]. In the cells of other tissues, fluoride has been shown to negatively influence many metabolic, structural, and functional cellular functions in experimental animal models in vivo and in cultured cells in vitro. The toxic fluoride effects include an induction of inflammatory reactions, cell contractile responses, inhibition of protein synthesis and cell cycle progression, oxidative stress, and DNA damage [17]. Many of these cellular events ultimately lead to cell death. NaFinduced apoptosis was demonstrated in the cells from different organs and tissues including lungs [25, 26], kidneys [27, 28], liver [29-31], brain [32-34], pancreas [35, 36], thymus [37], endometrium [38, 39], bone marrow [40], hair follicles [41], erythrocytes [42-44], as well as leukemic cells [45-47].

Apoptosis, or programmed cell death, is a complex and highly regulated phenomenon playing a key role in the elimination of unnecessary or damaged cell and in a variety of normal biological processes such as cell proliferation and differentiation, tissue homeostasis, and aging [48-50]. The morphological changes typical for apoptosis include condensation of nuclear chromatin, DNA fragmentation, disintegration of mitochondria, cell shrinkage, membrane blebbing, and formation of apoptotic bodies. The biochemical features include a delicate regulation of intracellular signaling pathways via gene expression and/or protein activity. The molecular mechanisms underlying fluoride-induced apoptosis are different by nature and include the stimulation of $G$ protein-dependent signaling systems, oxidative stress, ATP depletion, activation of the cell surface death receptors, disruption of outer mitochondria membrane, activation of caspases, alterations in the ratio of anti-apoptotic-apoptotic Bcl-2 proteins, upregulation of p53 expression, expression of apoptosis-related genes, endoplasmic reticulum stress and disturbances in protein synthesis (Figure 1). 


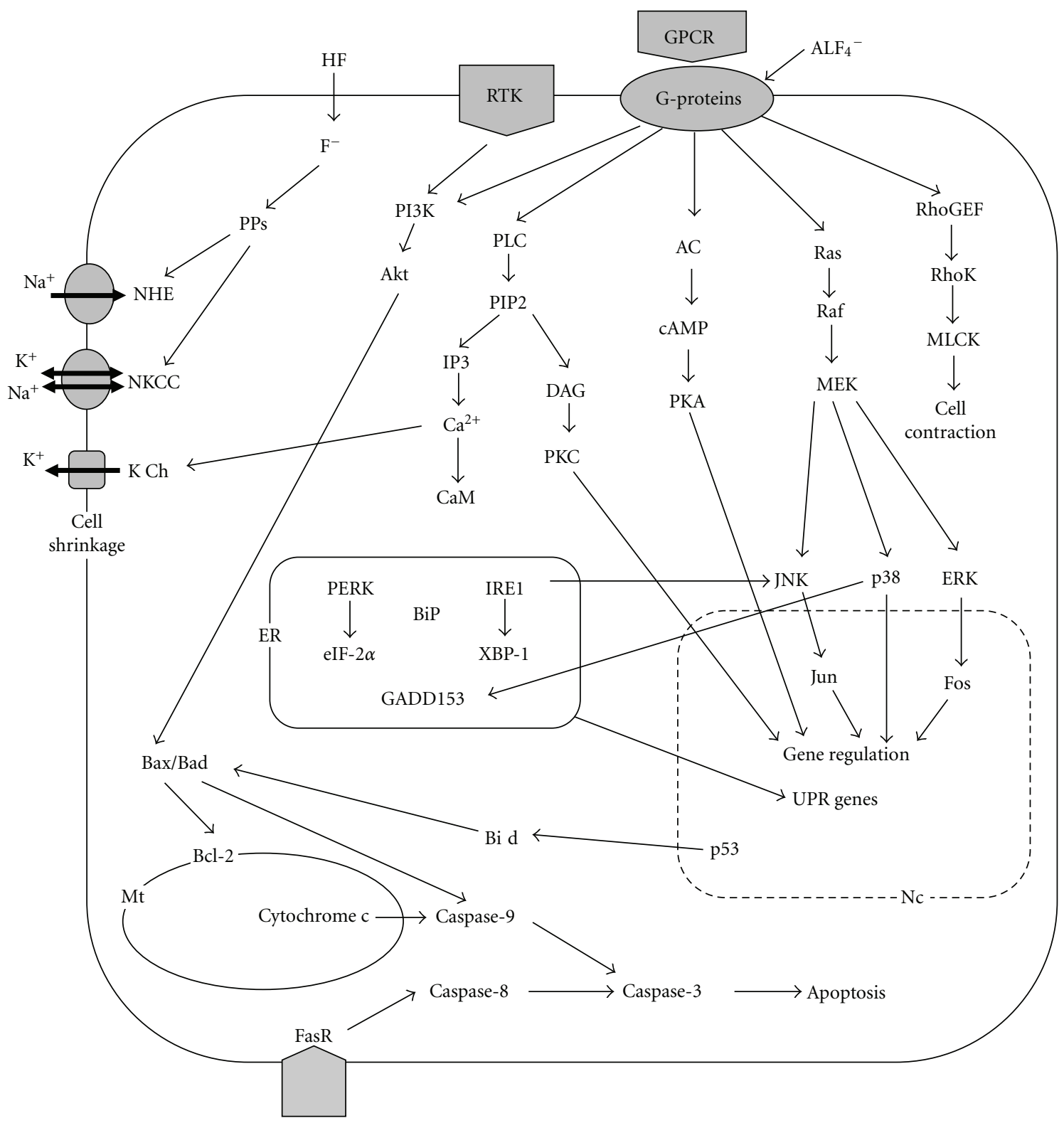

FIgURE 1: A simplified scheme of intracellular molecular mechanisms involved in fluoride toxicity and apoptosis. Nc: nucleus, ER: endoplasmic reticulum; Mt: mitochondria; RTK: receptor tyrosine kinase; GPCR: G protein-coupled receptor; FasR: Fas receptor; PI3K: phosphoinositol-3 kinase; Akt: Akt kinase; PLC: phospholipase C; PKC: protein kinase C; PIP2: phosphatidylinositol 4,5-biphosphate; IP3: inositol 1,4,5-triphosphate; DAG: diacylglycerol; CaM: calmodulin; AC: adenylyl cyclase; PKA: protein kinase A; RhoGEF: Rho guaninenucleotide exchange factor; RhoK: Rho kinase; MLCK: myosin light chain kinase; PERK: RNA-activated protein kinase-like ER kinase; IRE1: inositol-requiring protein-1; eIF2 $\alpha$ : eukaryotic translational initiation factor 2 subunit $\alpha$; Xbp-1: X-box binding protein 1; Bip/GRP78: $\mathrm{BiP} /$ glucose-responsible protein 78; GADD153: DNA damage-inducible protein; PPs: protein phosphatases; $\mathrm{K}_{\mathrm{Ch}} \mathrm{K}^{+}$channels; NKCC: $\mathrm{Na}^{+}-\mathrm{K}^{+}-2 \mathrm{Cl}^{-}$cotransport; $\mathrm{NHE}: \mathrm{Na}^{+} / \mathrm{H}^{+}$exchange.

\section{G Protein-Linked Signaling Pathways}

G proteins (guanine nucleotide-binding proteins) are a family of regulatory proteins involved in transmitting extracellular chemical signals from transmembrane G-protein-coupled receptors to intracellular targets by activating the cascades of second messengers. Fluoride was demonstrated to be a potent activator of G-proteins in virtually all studied cell types [51]. Initially, such activation by fluoride was described for heterotrimeric $\mathrm{G}$ proteins and has been proven to depend on the formation of multifluorinated complexes, $\mathrm{AlF}_{x}[52]$, formed in the water, food, and organism in the presence of trace amounts of aluminum after administration of sodium fluoride. The mechanism by which fluoroaluminates activate $G$ proteins is based on the structural and spatial similarity between $\mathrm{AlF}_{4}{ }^{-}$molecule and phosphate group $\mathrm{PO}_{4}{ }^{3-}$ [53]. As phosphate analog, $\mathrm{AlF}_{4}{ }^{-}$is able to affect the activities of a variety of ATP- and GTP-converting enzymes 
thus interfering with many metabolic reactions in the cells. Fluoroaluminate crosses the cell membrane and directly interacts with the membrane-associated inactive $\alpha$ subunit of $\mathrm{G}$ protein through the binding to $\beta$-phosphate of GDP mimicking the transition state of bound $\gamma$-phosphate [54]. The resulting $\mathrm{G} \alpha$-GDP- $\mathrm{AlF}_{4}{ }^{-}$complex resembles that of $\mathrm{G} \alpha$ GTP and thereby keeps the $\mathrm{G} \alpha$-protein in its active signaling conformation by inhibiting GTPase activity. Later, the monomeric low-molecular-weight $G$ proteins of the Ras superfamily (Ras, Rho, cdc42) have also been shown to associate with $\mathrm{AlF}_{4}^{-}[55,56]$. In this case, fluoroaluminate suppresses the activity of GTPase-activating proteins (GAPs), the enzymes that keeps Ras proteins in their inactive state by promoting the hydrolysis of bound GTP to GDP by virtue of GTPase reaction. The inactive GDP-bound forms of Ras proteins in the presence of aluminum fluoride form stable high-affinity complex Ras-GDP-AlFx-GAP, what results in the small $\mathrm{G}$ protein activation.

The types of large G-proteins implicated in the fluorideinduced cytotoxicity and cell death seem to be tissue specific. Four major subclasses of G-proteins have been described $\left(G_{\alpha s}, G \alpha_{i / o}, G \alpha_{q / 11}, G \alpha_{12 / 13}\right)$ distinguished from each other by sequence homology. As early as in 1985, Blackmore et al. [57] suggested that inhibition of some G protein (possibly $\mathrm{G} \alpha_{\mathrm{i}}$ ) by fluoroaluminate creates "some degree of regulatory chaos" in the rat hepatocytes. Lately, the role of $\mathrm{G} \alpha_{\mathrm{i}}$ protein in execution of toxic fluoride effects was demonstrated in the clonal RINm5F pancreatic $\beta$-cells and rat Langerhans islets, where apoptosis induced by $5 \mathrm{mM} \mathrm{NaF}$ was markedly enhanced by pretreatment with pertussis toxin (Ptx) modifying the $\alpha$-subunit of $\mathrm{G} \alpha_{\mathrm{i} / \mathrm{o}}$ family $[35,36,58]$. The rat proximal tubules also respond to fluoride through $\mathrm{G} \alpha_{\mathrm{i}}$ protein [59]. In contrast, Ptx did not augment the apoptosis of the lung A549 cells triggered by $5-10 \mathrm{mM} \mathrm{NaF}$ [26]. Although the nature of $G$ proteins in this study was not established, their activation was shown to be important since deferoxamine, $\mathrm{Al}^{3+}$ chelator, inhibited the apoptotic process, while an addition of $\mathrm{AlCl}_{3}$ facilitated it [26]. The generation of intracellular second messengers in fluorideexposed endothelial cells was also shown to be linked with a pertussis toxin-insensitive $G$ protein [60]. In osteoblastic cells, the fluoride-induced phosphorylation of cellular kinases was associated with expression of Ptx-sensitive $\mathrm{G} \alpha \alpha_{\mathrm{i} 2}$ and Ptx-insensitive $G$ proteins, the latter attributed to $G_{12}$ class $[61,62]$. Overall, these data indicate that almost all types of G-proteins are involved in the cellular responses to inorganic fluoride.

An implication of the small G-proteins in fluoride-induced cytotoxicity and cell death is studied less. However, a few available works have established a regulatory role of Ras/Rho in the NaF-mediated phosphorylation of myosin light chain kinase (MLCK) and MAP kinases in bovine pulmonary artery endothelial cells, what modulates the structure of F-actin cytoskeleton, contractile responses, and cell shape, the events directly linked with apoptotic processes $[63,64]$.

Activation of the large $G$ proteins by fluoride leads to subsequent stimulation of different $G$ protein-linked signal transduction pathways such as PKA-, PKC-, $\mathrm{Ca}^{2+}-$, PI3-, and Rho-kinase-linked systems, which presumably act in a coordinated manner and have been suggested to implicate in chemical-induced apoptosis, in a stimulatory or inhibitory manner, either directly or by triggering other pathways.

3.1. cAMP. cAMP (cyclic adenosine monophosphate) is the messenger of intracellular signaling system involving sequential activation of $\mathrm{G} \alpha_{\mathrm{s}} / \mathrm{G} \alpha_{\mathrm{i} / \mathrm{o}}$ proteins, adenylyl cyclase (AC), cAMP, and protein kinase A (PKA). An association between the cAMP/PKA signaling system and induction of cell death by fluoride was demonstrated for A549 cells [26], although authors suggest that elevation of cAMP as such was not sufficient to exert apoptosis but rather facilitated (enhanced) another fluoride-induced apoptotic pathway. A dose-dependent, saturable increase in cell death was observed after treatment of pancreatic RINm5F cells with the cell-permeable cAMP analog dibutyryl-cAMP suggesting that a sustained rise in intracellular cAMP may be a part of apoptosis-controlling system [35]. In contrast, NaF-induced decrease in the cAMP levels was described in osteoblasts [62] and rat hepatocytes [57], although the relation of such events to cell death was not a goal of these studies.

3.2. PKC. The effector of $\mathrm{G} \alpha_{\mathrm{q} / 11}$ protein is phospholipase $\mathrm{C}$ (PLC) which catalyzes the cleavage of membrane-bound phosphatidylinositol 4,5-biphosphate (PIP2) into the second messengers inositol 1,4,5-triphosphate (IP3) and diacylglycerol (DAG). DAG activates protein kinase C (PKC), an important second messenger able to phosphorylate many other proteins. A positive involvement of PKC in the NaFinduced cell death was demonstrated in the A549 cells and primary rat alveolar macrophages $[26,65]$, where NaFinduced apoptosis was accompanied by persistent increase in PKC activity, although the authors could not clarify whether the apoptotic effect was attributed to NaF-induced increase in PKC activity or only to permissive effects of the basal PKC activity. Garcia et al. [66] have shown that activation of Gprotein by $\mathrm{NaF}$ in the human endothelial cells produced a rapid and time-dependent translocation of PKC from the cytosol to the membrane. Unfortunately, the nature of PKC was not established in these studies. The PKC family consists of 10 members, and activation of specific PKC isoform in response to various stimuli has been shown to facilitate or suppress the cell death [67]. Hence, an implication of different PKC isoforms to the fluoride-induced cell death might be an interesting goal of future investigations.

3.3. $\mathrm{Ca}^{2+}$. An increase in intracellular $\mathrm{Ca}^{2+}$ concentrations is another consequences of $\mathrm{G} \alpha_{\mathrm{q} / 11}$ protein/PLC activation. IP3 binds to membrane receptors in the smooth endoplasmic reticulum, what facilitates the release of $\mathrm{Ca}^{2+}$. Many PKC isoforms are also activated by increases in intracellular $\mathrm{Ca}^{2+}$; thus both these pathways can converge to function through the same pathway. Elevated cytosolic $\mathrm{Ca}^{2+}$ also binds and allosterically stimulates protein calmodulin, which in turn activates $\mathrm{Ca}^{2+} /$ calmodulin-dependent kinases (CAMKs). An increase in $\mathrm{Ca}^{2+}$ concentration might be one of the common features for cytotoxicity and cell death either as a direct target or as indirect consequence of altered cellular processes $[68,69]$. 
Millimolar fluoride concentrations have been reported to increase intracellular $\mathrm{Ca}^{2+}$ concentration in the cells of many types including erythrocytes [44, 70], osteoblasts [71], proximal tubules [59], human neuroblastoma SH-SY5Y cells [72], and renal epithelial cell line NRK-52E [73] via release from intracellular $\mathrm{Ca}^{2+}$ stores, suppression of $\mathrm{Ca}^{2+}$-pump, or activation of $\mathrm{Ca}^{2+}$ channels. In the pulmonary artery endothelial cells, activation of pertussis toxin-insensitive $G$ proteins by $\mathrm{NaF}$ can initiate a series of events leading to increases in phosphoinositide hydrolysis and $\mathrm{Ca}^{2+}$ mobilization from intracellular stores [66]. Treatment of isolated hepatocytes with $2-10 \mathrm{mM} \mathrm{NaF}$ also produced a rise in free cytosolic $\mathrm{Ca}^{2+}$, decrease in PIP2 levels, and increase in IP3 and DAG levels [57]. The calmodulin-dependent pathway was shown to mediate NaF-induced enhancement of basal $\mathrm{Ca}^{2+}$ concentration in the rat glioma C6 cells [74].

A few works have established an important role of $\mathrm{Ca}^{2+}$ in the fluoride-induced cell death. A direct link between dose- and time-dependent increase in the concentration of free cytosolic $\mathrm{Ca}^{2+}$, measured with fluorescent $\mathrm{Ca}^{2+}$ indicator Fluo-3, and the transition of cell state to apoptosis and necrosis was demonstrated in the rat erythrocytes treated

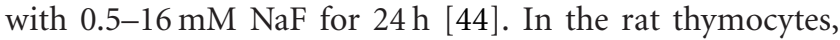
$10 \mathrm{mM} \mathrm{NaF}$ increased an intracellular $\mathrm{Ca}^{2+}$ content and the population of shrunken cells, although authors named the observed cell death as "apoptosis-like necrosis" [75]. The production of ROS in the human neuroblastoma $\mathrm{SH}$ SY5Y cells treated with $40-80 \mathrm{mg} / \mathrm{L} \mathrm{NaF}$ was mediated by an increase in cytosolic $\mathrm{Ca}^{2+}$ concentration due to release from intracellular calcium storage [72]. Xu et al. [76], investigating the relationship between $\mathrm{Ca}^{2+}$ and the development of fluorosis in experimental rats, suggested that increase in intracellular $\mathrm{Ca}^{2+}$ concentration might play a key role in the mechanism of renal injury and necrosis of renal tubules in fluorosis. In contrast, Sun et al. [77] established that low sperm hyperactivation of the mice exposed to high $\mathrm{NaF}$ doses was due to decrease in the cellular calcium concentration and suppression of the $\mathrm{Ca}^{2+} / \mathrm{CALM}-\mathrm{CAMK} 2$ signaling pathway, what authors explain by the lack of endoplasmic reticulum in sperm.

3.4. PI3-Kinase. Phosphatidylinositol $3^{\prime}$-kinase and especially its downstream effector Akt kinase until recently have been considered as the links of cell survival pathway due to their ability to inactivate proapoptotic molecules and modulate intracellular energy metabolism, although recent studies also established a certain role of PI3/Akt in the induction of cell death [78]. The role of PI3 kinase in the fluoride-induced cytotoxicity is not studied well but seems to be cell specific. Thus, treatment of the epithelial lung cells A549 with inhibitor of PI3 kinase wortmannin augmented their responses to NaF, indicating that activation of PI3 kinase is a survival factor [26]. In contrast, in the pancreatic RINm5F cells wortmannin failed to decrease the cell viability and did not attenuated the NaF-induced cell death [36].

3.5. Rho/Rho Kinase. The downstream effectors of $\mathrm{G} \alpha_{12 / 13}$ proteins are specific guanine-nucleotide exchange factors RhoGEFs, which stimulate small Ras G-proteins of the
Rho subfamily catalyzing the exchange of GDP for GTP [79]. Once bound to GTP, Rho can activate various proteins responsible for regulation and remodeling of the cell cytoskeleton such as Rho-kinases (RhoK), thus controlling cell shape, contractile responses, and migration. Thus, $20 \mathrm{mM} \mathrm{NaF}$ was shown to induce the barrier disfunction of bovine pulmonary artery endothelial cells via Rho/RhoKmediated MLC (myosin light chain) phosphorylation and actin cytoskeletal alterations [63]. Such RhoK-dependent MLC phosphorylation involves inactivation of the MLCP (MLC phosphatase) due to phosphorylation of the myosin phosphatase target subunit MYPT1. The contraction of rat aortic rings under influence of $4-8 \mathrm{mM} \mathrm{NaF}$ occurred via activation of the Rho/RhoK pathway and subsequent inactivation of MLCP was also associated with phosphorylation of MYPT1 and the PKC-potentiated inhibitory protein CPI17 [80].

\section{Tyrosine Phosphorylation}

Protein tyrosine kinases activated through receptor tyrosine kinases or G protein-coupled receptors are emerging as important modulators of the apoptotic response exerting both positive and negative effects in dependence on their concentration and cell type [81]. A positive role of tyrosine phosphorylation in the manifestations of toxic fluoride effects was established in A549 cells, where NaF-induced apoptosis was partially reduced by tyrosine kinase inhibitor genistein [26]. The proapoptotic effects of $\mathrm{NaF}$ in both RINm5F pancreatic cell line and human and rat pancreatic islet cells were also associated with the activation of genisteinsensitive tyrosine kinases $[36,58]$. In the fluoride-treated osteoblastic cells, pertussis toxin-insensitive $G$ proteins were suggested to activate several cytoplasmic protein tyrosine kinases from Src family, Pyk2 (proline-rich tyrosine kinase 2 ) and Fak (focal adhesion kinase) [61, 62], what modulates the adhesion properties of these cells and, consequently, differentiation, migration, and apoptosis. In contrast, $\mathrm{NaF}$ inhibited tyrosine kinase activity of insulin receptors purified from the rat skeletal muscles and human placenta by direct binding to the receptors [82].

\section{MAP Kinases}

MAPKs (mitogen-activated protein kinases), a group of protein serine/threonine kinases, are important components of a few signaling pathways regulating a wide variety of cellular processes including proliferation, differentiation, stress response, and apoptosis [83]. Three major subgroups composes the family of MAPKs: ERKs (extracellular signalregulated protein kinases), JNKs (c-Jun N-terminal kinases), and p38. MAPK cascades transmit extracellular stimuli from the cell-surface receptors to specific transcription factors in the nucleus where they regulate transcription through specific effectors. ERKs phosphorylate transcription factors TCF/ELK-1 and trigger c-Fos synthesis. JNK phosphorylates c-Jun and ATF (activating transcription factor), what stimulates their transcription activities. p38 phosphorylates HSP-27 and ATF1/2. ERK 1 and 2 are part of 
the Ras/Raf/MEKK/MEK pathway often associated with proliferation and survival, although the induction of apoptosis mediated via ERK has also been reported. The p38 and JNK kinases have been implicated primarily in the induction of apoptosis and inflammation after exposure to various chemical and biological agents, although their role also seems to differ between cells.

An involvement of MAP kinases in the fluoride-induced cytotoxicity and cell death was established in a few works, although their role may vary according to cell types. The stimulation of ERK by sequential activation of Rho/Raf$1 / \mathrm{MEK} / \mathrm{ERK}$ pathway was demonstrated in the pulmonary artery endothelial cells treated with $20 \mathrm{mM} \mathrm{NaF}$ [64]. In osteoblasts, stimulation of pertussis-toxin-sensitive $G_{i}$ protein by fluoroaluminate leads to activation of MAP kinases Erks and p70 S6 kinase involved in the regulation of gene transcription and protein synthesis, what results in osteoblast proliferation and differentiation [62]. Phosphorylation of some MAP kinase was also observed in the fluoride-exposed fibroblastic NIH3T3 cells [61]. In the human osteoblastlike TE85 osteosarcoma cells fluoride induced a sustained activation of ERK p44 [84]. In ameloblasts exposed to $10 \mu \mathrm{M} \mathrm{NaF}$, the JNK/c-Jun signaling pathway mediates the downregulation of metalloproteinase 20 (MMP-20), the protein responsible for the initial hydrolysis of amelogenin and regulation of the enamel matrix formation [85]. A direct correlation between the progression of apoptosis induced by $5 \mathrm{mM} \mathrm{NaF}$ and MAPKs activation was demonstrated in the MDPC-23 odontoblast-like cells [21] and human epithelial lung A549 cells [25]. In both cases all studied MAPKs were phosphorylated before progression of apoptosis; however, the pattern of MAPK phosphorylation in these two cell types was different. Thus, NaF-induced apoptosis in MDPC-23 odontoblast-like cells was associated primarily with JNKs (p54 and p46) and, less significantly, with ERKs (p44 and p42) pathways, whereas the role of p38 was not evident [21]. In the A549 epithelial lung cells, p38 and possibly JNK were suggested to be positively involved in NaF-induced apoptosis, whereas ERK activation seems to counteract this process [25]. An implication of MAPKs in fluoride toxicity was also confirmed by in vivo studies. Thus, the comparative study of p38 MAPK signal transduction pathway in the peripheral blood mononuclear cells from patients with coalcombustion-type fluorosis established that the expressions of p38 in PBMC from subjects suffering from fluorosis were significantly increased as compared to other groups [86]. An increased level of apoptotic cells in the brain of fluorideintoxicated rats, as well as fluoride-treated SH-SY5Y cells, positively correlated with phosphorylation of JNK [34].

\section{Inhibition of Protein Phosphatase Activities}

Protein phosphatases (PPs) comprise a large family of enzymes divided into subfamilies of tyrosine phosphatases, serine/threonine phosphatases, and lipid protein phosphatases [87, 88]. Protein phosphatases dephosphorylate intracellular proteins by removing phosphate groups from substrate residues, thereby counteracting the effects of protein kinases. The reversible posttranslational modifications of intracellular proteins by coordinated and reciprocal action of protein kinases and protein phosphatases represent a fundamental regulatory mechanism for many biological processes including cell proliferation and cell death. The involvement of protein phosphatases in cell death is well established. The tyrosine phosphatases and lipid phosphatases were shown to be the most important regulators of Fas- (CD95)dependent apoptosis due to their ability to control DISC formation or Akt activation [87]. Protein serine/threonine phosphatases PP1 and PP2A are implicated in the regulation of both CD95 and mitochondrial apoptotic pathways. All levels of MAPK signaling can be regulated by protein phosphatases; for instance, PP2A can dephosphorylate and inactivate both MEK1,2 and ERK1,2 proteins [88].

Fluoride was shown to be potent nonspecific inhibitor of protein phosphatases [89]. Unfortunately, the investigations elucidating the role of PPs inhibition in the development of fluoride-induced apoptosis were not performed to date. On the other hand, the capacity of fluoride to inhibit PPs is known to be associated with the alterations in the transmembrane ion transport mediated by a variety of ATPases, carriers and channels. Such changes in the activities of ion transporters might lead to an imbalance in the ionic gradients across the plasma membrane and disturbances in membrane potential, the early events in the activation and progression of apoptotic cascade [90]. Our recent results demonstrate that $\mathrm{NaF}$ exerts diverse and complicated effects on $\mathrm{K}^{+}$and $\mathrm{Na}^{+}$transport across the membrane of rat erythrocytes $[91,92]$. Thus, treatment of these cells with $20 \mathrm{mM} \mathrm{NaF}$ led to substantial loss of cellular $\mathrm{K}^{+}$, probably provided by the opening of $\mathrm{Ca}^{2+}$-activated $\mathrm{K}^{+}$ channels, and almost complete inhibition $\mathrm{K}^{+}$influx through $\mathrm{Na}^{+} / \mathrm{K}^{+}$pump. In contrast, $\mathrm{Na}^{+}$influx in the rat erythrocytes, mediated by Na-K-2Cl cotransport and $\mathrm{Na}^{+} / \mathrm{H}^{+}$exchange activities, was stimulated when protein dephosphorylation was inhibited. These results are in agreement with the data obtained on duck erythrocytes, where $10 \mathrm{mM} \mathrm{NaF}$ considerably enhanced the activity of $\mathrm{Na}-\mathrm{K}-2 \mathrm{Cl}$ cotransport [93]. The $\mathrm{K}-\mathrm{Cl}$ cotransport is also regulated by PPs; for example, its activity in the frog erythrocyte membrane was suppressed when PPs were inhibited with fluoride [94]. Cell sodium overload might further stimulate $\mathrm{H}^{+}$influx via $\mathrm{Na}^{+} / \mathrm{H}^{+}$exchange and induce acidification of intracellular milieu, as well as increase the cytosolic $\mathrm{Ca}^{2+}$ concentration due to activation of $\mathrm{Na}^{+} / \mathrm{Ca}^{2+}$ exchanger. $\mathrm{K}^{+}$loss is widely associated with cell shrinkage or apoptotic volume decrease. Early phosphatidylserine exposure during apoptosis was also reported to be dependent on $\mathrm{Na}^{+}$influx. Moreover, membrane transport proteins are closely associated with the cortical cytoskeleton, and their activities can affect the phosphorylation of cytoskeleton elements; thus, $\mathrm{Na}^{+}$overload has been demonstrate to activate the Rho-ROCK signaling pathways which are necessary for apoptotic body formation (see [90]).

\section{Oxidative Stress}

Generally, this term describes an imbalance between oxidative damage in the cell, produced by reactive oxygen species 
(ROS), and the status of intracellular antioxidant systems. Chronic or acute ROS overproduction, exceeding the capacity of cellular antioxidant defense systems, causes oxidative damage to macromolecules such as DNA and proteins, peroxidation of membrane phospholipids, and mitochondrial depolarization, thus initiating apoptosis and organ lesions. The main ROS implicated in the tissue injury are superoxide anion, $\left({ }^{\circ} \mathrm{O}_{2}{ }^{-}\right)$generated in mitochondria, hydrogen peroxide $\left(\mathrm{H}_{2} \mathrm{O}_{2}\right)$ produced from $\mathrm{O}_{2}$ by the action of superoxide dismutase, hydroxyl radical $\left(\mathrm{OH}^{-}\right)$produced from the decomposition of hydroperoxides, and peroxynitrite $\left(\mathrm{ONOO}^{-}\right)$generated by the reaction of $\mathrm{O}_{2}$ with nitric oxide (NO). To prevent oxidative stress, continuously produced ROS is scavenged by the cellular antioxidant defense enzymes, most important of which are superoxide dismutase (SOD), catalase (CAT), and glutathione peroxidase (GSH-Px). SOD quenches ${ }^{\bullet} \mathrm{O}_{2}{ }^{-}$into corresponding $\mathrm{H}_{2} \mathrm{O}_{2}$ and $\mathrm{H}_{2} \mathrm{O}$. CAT accelerates the dismutation reaction of $\mathrm{H}_{2} \mathrm{O}_{2}$ followed by the formation of $\mathrm{H}_{2} \mathrm{O}$ and $\mathrm{O}_{2}$. GSHPx participates in the reactions destroying hydrogen peroxide, organic peroxide, free radicals, and certain foreign compounds. Intracellular redox status also depends on the ratio between reduced and oxidized glutathione GSH/GSSG maintained by coordinated activities of glutathione (GSH) antioxidant enzymes-glutathione reductase (GR) and GSHPx. The decreased GSH/GSSH ratio is a hallmark of oxidative stress and apoptosis [95]. An ability of oxidative stress to provoke cell death has also been associated with the lipid peroxidation (LPO), the process of oxidative degradation of lipids in which free radicals "steel" electrons from membrane lipids, resulting in their damage, especially polyunsaturated fatty acids, what may impair a variety of intra- and extramitochondrial membrane transport systems thus contributing to apoptosis. LPO can be determined as lipid peroxidation byproducts MDA (malondialdehyde) by thiobarbituric acid reactive substance (TBARS) assay.

Oxidative stress is a recognized mode of fluoride action in some cell types. An involvement of increased ROS production and lipid peroxidation in the fluoride-induced apoptosis has been proven in vitro in many cultured cell types as well as in vivo in experimental animals and in people living in areas of endemic fluorosis $[17,96]$. Fluoride may induce the generation of superoxide anion $\left({ }^{\circ} \mathrm{O}_{2}{ }^{-}\right)$as well as its downstream consequences such as hydrogen peroxide, peroxynitrite, and hydroxyl radical $\left(\mathrm{OH}^{-}\right)$. However, the role of oxidative stress in fluoride-induced apoptosis is now under discussion because some studies have described the lack of ROS production during fluoride-induced apoptosis. For example, Reddy et al. [97] did not observed significant difference in lipid peroxidation, glutathione, and vitamin $\mathrm{C}$ in blood of the patients suffering from endemic fluorosis and fluoride-intoxicated rabbits as compared to the controls. Lee et al. [98] also did not show ROS production in the $\mathrm{NaF}$-treated human gingival fibroblasts.

7.1. ROS. An elevated ROS generation was shown to implicate in both apoptosis and necrosis, although the type of cell death and nature of ROS produced in the cells seem to depend on the concentration of fluoride ions. The positive correlation between F-induced apoptosis and production of ${ }^{-} \mathrm{O}_{2}{ }^{-}$was demonstrated in the spermatozoa of rats administered $5 \mathrm{mg} \mathrm{F} / \mathrm{kg}$ of body weight $[99,100]$ and mouse pancreatic $\beta$-cells exposed to $1.35-2.26 \mathrm{mM} \mathrm{F}$ [101]. In contrast, ${ }^{\bullet} \mathrm{O}_{2}{ }^{-}$accumulation in the $\mathrm{NaF}$-treated rat erythrocytes appears to be an indicator of necrotic processes, while the apoptotic cell state was mediated by peroxides, most probably $\mathrm{H}_{2} \mathrm{O}_{2}$ (Agalakova and Gusev, unpublished data). The dose-dependent ROS generation was reported in leucocytes, where ${ }^{\circ} \mathrm{O}_{2}{ }^{-}$prevails at high fluoride and $\mathrm{OH}^{-}$dominates at low fluoride concentrations [102]. 3-10 $\mu \mathrm{M} \mathrm{NaF}$ was able to increase overall ROS production and trigger apoptosis in the cultured human macrophages [103], while high $\mathrm{NaF}$ concentration $(100 \mathrm{mM})$ induced ROS-associated necrotic death of murine hepatocytes [104]. In vivo studies confirmed an involvement of ROS in the fluoride toxicity. Thus, elevated ROS was suggested to be one of the causes of apoptosis and cell cycle changes in the oral mucosa cells and hepatocytes from fluoride-intoxicated rats [31]. An enhanced production of ROS attributed to peroxides was demonstrated in the blood, liver, kidneys, and brain of rats consuming excessive fluoride amounts with drinking water $[42,43]$. The significant morphological abnormalities and apoptosis associated with increased ROS generation were also observed in the sperm cells of mice exposed to high fluoride doses [105].

7.2. Lipid Peroxidation. Another important, although indirect, mechanism of fluoride-induced cytotoxicity demonstrated in the cells of many tissues is lipid peroxidation (LPO). The significant LPO was reported in RBCs from children and adults afflicted with endemic fluorosis [106, 107]. Wistar rats, exposed to high fluoride doses, also showed enhanced LPO in their RBCs [108-111], liver [108, 110, 111], and brain $[108,110]$. Karaoz et al. [112] showed that exposure of the pregnant rats and their offsprings during first month of life to fluoride leads to kidney tissue changes and LPO in the first and second generation of rats. A direct link between fluoride-induced apoptosis and elevated LPO was shown in the pig [30] and rat [31] hepatocytes. Fluoride administration to female Wistar rats triggered apoptosis in endometrial tissues and significantly increased endometrial MDA content $[38,39]$. The reduced fertility of male rats subchronically exposed to fluoride was accompanied by $\sim 50 \%$ increase in spermatozoa LPO [99]. Fluoride-induced apoptosis of hair follicles was also associated with increased level of LPO exhibited as increased MDA content [41].

In vitro experiments also confirmed an ability of fluoride to induce LPO. The significant increase in MDA level followed by decrease in viability was reported in the mice primary calvarial osteoblasts exposed to $\mathrm{NaF}$ [113]. An increase in MDA content was associated with the fluorideinduced apoptosis of the human embryo hepatocytes L-02 cells [29], human leukemia HL-60 cells [45], and necrosis of murine hepatocytes [104].

7.3. Glutathione. GSH depletion is generally attributed to an imbalance between pro-oxidant and antioxidant activities inside the cell and overproduction of ROS at the mitochondrial level leading to the damage of cellular components. 
However, the information on relationship between fluoride and alterations in the GSH content is contradictory and inconclusive. For instance, decreased GSH level was reported in the RBCs of children with endemic fluorosis [106]. Fluoride-induced apoptosis was associated with depletion of the GSH/GSSH ratio in the blood, liver, kidney, and brain of experimental rats that received high fluoride doses with drinking water $[42,43]$. The pronounced decrease in GSH content was observed in the human embryo hepatocyte L-02 cells [29], hepatocytes of fluoride-intoxicated rats [31], and murine hepatocytes [104]. On the other hand, GSH level in the blood or RBCs from fluorotic humans and fluorideintoxicated rodents was also reported to be elevated [108, 114] or unaltered [97]. Two-phase alterations in the GSH content were observed in the NaF-treated rat erythrocytes (Agalakova and Gusev, unpublished data). In these cells, NaF-induced apoptosis was accompanied by depletion of GSH content, possibly attributed to GSH oxidation and plasma membrane GSSG efflux, while the transition of cells to necrotic state was associated with increase in GSH level, probably due to suppression of GSH transporters.

7.4. Antioxidant Enzymes Activity. Alongside with aforementioned oxidative stress-related events, fluoride is proven to alter the activity of many antioxidant enzymes such as SOD, GSH-Px, and CAT, playing an important role in the antioxidative cell defense and eliminating free radicals. A decrease in the activity of free radical scavenging enzymes, SOD, CAT, GST, and GSH-Px, was found in the blood of people living in areas of endemic fluorosis [106, 107, 115]. A significant decrease in SOD activity was observed in the rat and mice erythrocytes after long-term high-fluoride intake [108, 109, 116]. Administration of $\mathrm{NaF}$ to experimental animals also led to decrease in the activities of SOD, CAT, GST, or GSH-Px in the liver [104, 117, 118], kidneys [117], and brain [119]. Fluoride-intoxicated female albino Wistar rats exhibited significantly decreased endometrial SOD, GSH-Px, and CAT activities [39]. In the NaF-treated primary calvarial mice osteoblasts, CAT, SOD, and GSHPx showed elevated activities in response to low $\mathrm{NaF}$ doses, what might be associated with the tissue-specific beneficial property of fluoride for bone tissue, but were significantly suppressed at high fluoride concentrations [113].

7.5. Other Biochemical Changes. The fluoride-induced cytotoxicity was demonstrated to be associated with elevated $\mathrm{NO}$ generation in the serum of chicks treated with graded doses of sodium fluoride [120] and in the liver of fluorideintoxicated rats [118]. NO, an important signaling molecule, can react with superoxide to form peroxynitrite, while reacting with thiols and metal centers in proteins to form nitrosyl adducts. In the $\mathrm{C} 6$ rat glioma cells, $\mathrm{NaF}$ enhances cGMP generation via nitric oxide synthase (NOS), an enzyme catalyzing the production of $\mathrm{NO}$ from $\mathrm{L}$-arginine on expense of NADPH [73]. In the rat spermatozoa, fluoride increased the activity of NADPH oxidase, another enzyme, contributing to ROS generation [100]. An increase in the level of lactate dehydrogenase (LDH), often used as a marker of tissue breakdown, was demonstrated in the NaF-treated
SH-SY5Y cells [71] and in the plasma of rats kept on high-fluoride diet [118]. Among other cellular compounds described to be affected by fluoride are transaminases (AST and ALT), creatine kinase (CK), total lipids (TLs), cholesterol, triglycerides (TGs), and low-density lipoproteincholesterol (LDL-c), which amounts increased in the plasma of fluoride-intoxicated rats, while the content of high-density lipoprotein-cholesterol (HDL-c) decreased [118]. The RBCs of rats exposed to fluoride in drinking water exhibited significant inhibition of the parameters related to heme synthesis pathway like $\delta$-aminolevulinic acid dehydratase and $\delta$-aminolevulinic acid synthetase, accompanied by the depletion of whole brain biogenic amine levels [43].

\section{ATP Depletion}

The decline in cellular ATP level is a well-known indicator of the cell senescence and death [121]. ATP is generated by glycolysis and oxidative phosphorylation. Fluoride is a wellknown inhibitor of enzymes of glycolytic pathway, first of all enolase [122]. Although this effect is known since 40 years of the twentieth century, it is often underestimated or ignored in the studies of fluoride cytotoxicity and cell death. A few works reported the significant (70-90\%) decrease in ATP content in the human [123] and rat (Agalakova and Gusev, unpublished data) erythrocytes, oral mucosal fibroblasts [124], and macrophages [103] in in vitro studies; however, the direct link between NaF-induced inhibition of glycolysis and apoptosis was established only in the HL-60 cells exposed to 7.5-20 mM NaF [47]. Since energy supply is a limiting factor in a variety of biochemical processes, ATP depletion can arrest many crucial cellular functions like transmembrane ion transport and protein phosphorylation, disturb membrane potential, and membrane-cytoskeleton interactions, what may finally lead to cell death $[17,50]$. In erythrocytes, which lack nuclei and mitochondria and which energy requirements completely depend on glycolysis, an inhbition of glycolysis is especially dangerous. For example, ATP depletion induced by $0.5-20 \mathrm{mM} \mathrm{NaF}$ led to inhibition of $\mathrm{Na}^{+}-\mathrm{K}^{+}$-pump, accumulation of free cytosolic $\mathrm{Ca}^{2+}, \mathrm{Ca}^{2+}$ dependent $\mathrm{K}^{+}$loss, and shrinkage of the rat erythrocytes [44, 92]. GSH synthesis and GSH/GSSG membrane transport are also ATP dependent [95]; thus ATP depletion might be the primary process in the chain of events impairing GSH replenishment and antioxidant defense.

\section{Caspases}

The central role in the molecular events, implicated in development and regulation of cell death, belongs to caspases, a unique and closely related family of cysteine proteases $[48,49]$, which can be divided into initiator $(-2,-8,-9$, $-10)$ and effector $(-3,-6,-7)$ caspases. The caspases function by a cascade, in which initiator caspases are activated by a variety of lethal stimuli generated at the cell membrane or inside the cells in microenvironment of particular organelles. Initiator caspases activate a set of effector caspases by their cleavage at specific target sites. The cleavage events are responsible for the most of morphological changes associated 
with apoptosis. Caspases substrates include the cytoskeletal proteins, Rho kinase isoform ROCK-1 which activation results in the blebbing of apoptotic cells [125], focal adhesion kinase (FAK) which cleavage leads to the loss of substrate contact [126], and cytoplasmic chaperone inhibitor of caspase-activated DNAse (ICAD) which stimulation releases a nuclease from its anchor within the cytoplasm and permits its arrival to the nucleus with subsequent cleavage and condensation of DNA [127].

Caspase-dependent apoptosis occurs through two main interconnected pathways - intrinsic mitochondria-mediated pathway and extrinsic death receptor-mediated pathway. The mitochondrial pathway is initiated by the disruption of outer mitochondrial membrane by apoptotic stimuli with subsequent release of cytochrome $\mathrm{c}$ from mitochondria to cytosol, which interacts with Apaf-1 (apoptotic proteaseactivating factor) and dATP (deoxyadenosine triphosphate) to form apoptosome and activate caspase-9, which in turn activates caspase-3 [128]. The death receptor pathway is stimulated through association of transmembrane death receptors TNF- $\alpha$ or Fas and their ligands. The receptors aggregate and recruit adaptor molecules such as Fas-associated death domain (FADD). These events lead to formation of the death-inducing signaling complex (DISC) and activation of caspase- 8 with subsequent stimulation of caspase- 3 . Thus, intrinsic and extrinsic pathways converge at the activation of caspase-3, which cleaves one of its substrates, poly(ADPribose) polymerase (PARP), resulting in concomitant degradation of nuclear DNA.

An ability of fluoride to trigger an intrinsic mitochondria-mediated death pathway has been demonstrated in many cell types both in vitro and in vivo. Thus, an exposure of the human promyelocytic HL-60 cells to $2-5 \mathrm{mM} \mathrm{NaF}$ led to significant increase in the level of cytosolic cytochrome c, activation of caspase- 3 , and subsequent cleavage of intact PARP leading to DNA damage $[45,46,129]$. In the same cells, Otsuki et al. [47] reported an increased activity of caspase-9. The similar activation of caspase-3, cleavage of PARP, and DNA fragmentation were observed in the MDPC23 odontoblast-like cells exposed to $5 \mathrm{mM} \mathrm{NaF}$ [21]. Application of $20-40 \mathrm{mM} \mathrm{NaF}$ to the human gingival fibroblasts promotes an expression of VDAC-1 (voltage-dependent anion channel), a major component of mitochondrial permeability transition pore, and increased the level of cytochrome $\mathrm{c}$ released into cytosol, what results in the stimulation of mitochondrial cell death pathway through activation of caspases-3 and -9 and cleavage of PARP [98]. Millimolar concentrations of $\mathrm{NaF}$ were found to induce a caspase-3mediated DNA fragmentation in ameloblast-derived cell line LS8 [18]. The fluoride-induced apoptosis in the neonatal rat osteoblasts was found to be associated with elevated expression of caspase- 3 and caspase-9 mRNA [23].

An ability of fluoride to trigger the mitochondria-dependent apoptosis on the level of intact organism is studied in lesser degree. Nevertheless, an excessive fluoride ingestion by Wistar rats induced a significant upregulation of caspase3 and caspase- 9 mRNA expression levels in thymus cells and induced thymus apoptosis [37]. Considerable enhancement of both caspase- 9 and caspase- 3 activities, indicating that fluoride induced caspase-dependent apoptosis, was also observed in the hepatocytes of fluoride-intoxicated pigs [30].

Recent studies also demonstrated an involvement of extrinsic death receptor-dependent pathway in the development of fluoride-induced apoptosis. Thus, in parallel with activation of caspase- 9 , an increased activity of caspase- 8 was observed in the NaF-treated human gingival fibroblasts [98] and HL-60 cells [47]. NaF-induced apoptosis of the human gingival fibroblasts was also found to be associated with upregulation of Fas-L levels [98]. The enhanced expression levels of Fas, Fas-L, and caspase-8 mRNA and concomitant activation of activity caspase- 3 were demonstrated in the human neuroblastoma SH-SY5Y cells treated with $40-80 \mathrm{mg} / \mathrm{L}$ $\mathrm{NaF}$ [130]. The conflicting results were obtained in the work of Jacinto-Alemán et al. [20] who described an increased expression of caspase- 3 and -8 in murine thirty first molar germs culture with $5 \mathrm{mM} \mathrm{NaF}$ but suggested that fluoride-induce apoptosis in these cells is related to oxidative stress due to reduction of the enzymatic antioxidant. The stimulation of caspase-3 not attributed to either intrinsic or extrinsic pathways has been described in the leucocytes of fluoride-intoxicated rats [131] and osteoblast-like MC3T3E1 cells [132]. However, fluoride was also reported to fail to activate caspase-3 in the MC3T3-E1 cells [133].

\section{Bcl-2 Family Proteins}

Other key components involved in apoptotic signaling upstream of caspases are the proteins of Bcl-2 (B-cell lymphoma/leukemia-2) superfamily $[49,134]$. Anti-apoptotic members of $\mathrm{Bcl}-2$ (such as Bcl-2 and $\mathrm{Bcl}-\mathrm{X}_{\mathrm{L}}$ ) are mainly integral proteins in the mitochondrial, endoplasmic reticulum, and nuclear membranes. The majority of proapoptotic Bcl2 proteins (such as Bax, Bad, and Bid) are localized in the cytosol, but following a death signals they undergo a conformational change and integrate into mitochondria outer membrane. The regulation at the transcriptional level seems to be a critical factor for equilibrium between these pro- and antiapoptotic proteins that influences cell susceptibility to death signals; for example, Bax is transcriptionally responsive to p53 induction. The Bcl-2 family controls the release of critical molecules from the mitochondrial intermembrane space to cytosol by regulation of the mitochondrial permeability transition pore. Amongst released molecules are cytochrome $\mathrm{c}$ and dATP, which together activate caspase-9 by association with Apaf-1 protein. Bcl-2 phosphorylation has also been shown to regulate the generation of ROS and subsequent inhibition of cell cycle progression.

An implication of $\mathrm{Bcl}-2$ proteins in the regulation of fluoride-induced apoptosis was convincingly proved in the cells of different types. A few works performed on the human promyelocytic leukemia HL-60 cells have established that $10-15 \mathrm{mM} \mathrm{NaF}$ promotes either a gradual upregulation of proapoptotic Bad protein [47] or downregulation of antiapoptotic $\mathrm{Bcl}-2$ protein $[45,46]$. The similar picture was observed in the human gingival fibroblasts and human oral squamous carcinoma cells, where the apoptosis induced by 5-40 $\mathrm{mM} \mathrm{NaF}$ was also associated with the downregulation of antiapoptotic Bcl-2 [98] or enhanced expression and 
dephosphorylation of Bad protein [135]. Elevated expression of another proapoptotic member Bax and corresponding suppression of $\mathrm{Bcl}-2$ expression at both the mRNA and protein levels have been shown to implicate in apoptosis in the NaF-treated renal tubules [27] and osteoblastic MC3T3E1 cells [24], as well as in the oral mucosal cells of rabbits that underwent topical application of fluoride-containing gel [136]. Immunoexpression of both Bax and Bid proteins was also described in the thirty first molar germs from 1-day-old Balb/c mice cultured with $5 \mathrm{mM} \mathrm{NaF} \mathrm{[20].}$ Activated form of Bid, tBid, triggers the oligomerization of $\mathrm{Bax} / \mathrm{Bad}$ and induces the release of cytochrome $\mathrm{c}$ from mitochondria. Overall, these results indicate that fluorideinduced apoptosis is mediated by its direct effects on the expression of bcl-2 family members resulting in decrease in the antiapoptotic/proapoptotic proteins ratio. However, Gutiérrez-Salinas et al. [131] did not find statistically significant differences between the Bcl-2 expression levels in leucocytes from control and F-intoxicated rats.

\section{1. p53 Protein}

The p53 tumor suppressor protein is a transcription factor responding to numerous extrinsic and intrinsic stress stimuli, including DNA damage, oncogene activation, and hypoxia. Although initially p53 has been described as an inductor of cell cycle arrest and apoptosis, recent studies have emerged its role to the regulation of normal metabolic homeostasis, senescence, fertility, differentiation, and regulation of stem cells $[137,138]$. By activating the specific transcriptiondependent and transcription-independent pathways in nuclei and mitochondria, p53 is able to mediate the expression of various apoptosis-related proteins such as $\mathrm{Bcl}-2$, Fas, and Bax, control the mitochondria redox balance and integrity, and contribute to the regulation of oxidative phosphorylation, glycolysis, nucleotide biosynthesis, fatty acid oxidation, and antioxidant response.

Information on involvement of p53 protein in the development of fluoride-induced apoptosis is scarce. Nevertheless, Wang et al. [139] investigated the link between apoptosis and p53 expression in the human embryo hepatocytes and found that application of $40-160 \mu \mathrm{g} / \mathrm{mL} \mathrm{NaF}$ exerted a dosedependent rise in expression levels of both p53 protein and p53 mRNA accompanied by the fall in cell survival rate. The leucocytes of rats exposed to $50 \mathrm{ppm}$ fluoride also exhibited a markedly increased expression of p53 protein [131]. However, the upstream pathways leading to excessive p53 expression under fluoride influence are yet to be elucidated.

\section{Gene Expression}

Recent studies in vivo and in vitro indicate that fluoride is a transcriptional modulator in several cell types, both normal and pathological. Using cDNA array test, SalgadoBustamante et al. [140] analyzed the expression of approximately 180 genes related to apoptosis and inflammation in peripheral blood mononuclear cells (PBMC) from Mexican human individuals exposed to high fluoride concentration in drinking water. Authors found a significant downregulation of apoptosis-related genes from TNF ligand family (TNFa, FasL, CD30L, CD40L, 4-1BBL, TANK, TRAIL), TNF receptor family (DR3, HVEM), caspase family (Caspase-2, Caspase-6), TRAF family (TRAF-2 and TRAF-5), and CIDE family (CIDE-A and CIDE-B), and upregulation of survivin (BIRC5) from IAP family, which is a regulator of the cellcycle and apoptosis. In addition, the expression of several pro- and anti-inflammatory genes was altered in this group of residents from a fluoride-endemic area of Mexico.

An experiment on laboratory animals also established the capacity of fluoride to exert transcriptional effects. Thus, gene expression profiling of the sperm cells from fluorideexposed mice has shown that 34 studied genes were upregulated and 63 genes were downregulated, most of which are involved in the signal transduction, amino acid phosphorylation, oxidative stress, cell cycle, electron transfer, glycolysis, chemotaxis, spermatogenesis, and apoptosis [105]. Comparative proteomic analysis of the kidney, liver, and cardiac muscle samples from puffer fish Takifugu rubripes exposed to excessive fluoride has revealed that among a few tens of proteins, found to be either upregulated or downregulated, five or more proteins seem to be involved in apoptosis and other functions associated with fluorosis [141143]. Those are disulfide isomerase ER-60 playing a key role in the degradation of misfolded proteins and refolding of denatured proteins in ER, SMC3, and SMC4 proteins taking part in DNA recombination and repair, as well as chromosome segregation, 4NSc-Tudor domain protein (nuclear factor kappa B2 NF-kB2) which proapoptotic function is stabilization of p53, cyclin D1, a nuclear protein repressed by p53 and required for cell cycle progression, MAPK10 (c-Jun N-terminal kinase 3 JNK3), thought to phosphorylate p53 and playing an important role in nuclear signal transduction associated with apoptosis [144-147]. Alterations in these proteins activities can trigger apoptotic cascade involving p53, what leads to chromosomal instability and activation of the p53-dependent mitotic checkpoint, that is, disturbance of normal cell cycle and induction of apoptosis. Zhang et al. $[33,148]$, studying the mechanisms underlying the neurotoxicity of fluorosis on the primary rat hippocampal neurons, reported that high fluoride intake, in addition to DNA damage and cell-cycle regulation, suppressed the expression of neural cell adhesion molecules (NCAMs), necessary for the maintenance of cognitive functions of brain such as learning and memory, but enhanced the gene expression of $\mathrm{NF}-\kappa \mathrm{B}$, the transcription factors which can both promote cell death in response to oxidative stress, thus contributing to neurological dysfunctions.

\section{Endoplasmic Reticulum Stress}

The endoplasmic reticulum (ER) is a principal site for folding and maturation of transmembrane, secretory, and ERresident proteins. The prolonged perturbations in ER homeostasis, such as accumulation of misfolded and unfolded proteins, lead to ER stress which activates the self-protecting mechanisms termed unfolded protein response (UPR) responsible for either alleviating ER stress or for inducing apoptosis $[149,150]$. UPR is mediated through three parallel 
integrated intracellular pathways starting from ER-stress sensors, PERK (RNA-activated protein kinase-like ER kinase), IRE1 (inositol-requiring protein-1), and ATF6 (activating transcription factor-6). PERK phosphorylates the eIF2 $\alpha$ (eukaryotic translational initiation factor 2 subunit $\alpha$ ), what transiently attenuates protein translation and reduces ER overload. IRE1 (inositol-requiring protein-1) is a proapoptotic initiator. IRE1 initiates RNAse activity specific for Xbp1 mRNA splicing, what results in encoding of active Xbp-1, a transcription factor activating the transcription of molecular chaperones such as Bip/GRP78 (BiP/glucose-responsible protein 78 ). Once the unfolded proteins accumulate in ER, $\mathrm{BiP}$ is released into lumen and binds to hydrophobic regions on the surface of the unfolded proteins to facilitate proper folding and augment the folding capacity of ER. Activated IRE1 also triggers JNK/AP-1/GADD153-signaling pathway, which recruits Jun N-terminal inhibitory kinase (JIK) and TRAF2 to activate apoptosis-signaling kinase 1 (ASK1), which in turn activates JNK and mitochondria/Apaf1dependent caspase cascades. The stress response gene GADD153 (DNA damage-inducible protein) plays a critical role in cell survival or cell death as part of the UPR and is generally considered a proapoptotic factor, inducing cell death by promoting protein synthesis and oxidation in the stressed ER. GADD153 suppresses activation of the Bcl-2 and NF- $\kappa$ B. ATF6 is a transcription factor which collaborates with XBP1 and ATF4 to activate the UPR target genes thus controlling cell response to ER stress and activation of ERassociated degradation of accumulated unfolded proteins. UPR-mediated cell survival or cell death is regulated by the balance of GRP78 and expression of GADD153/CHOP.

The series of works performed on the mouse ameloblastderived LS8 cells $[18,151,152]$ presented clear evidences that fluoride is able to induce ER stress and UPR involving an increased expression of PERK, eIF2 $\alpha$, IRE1, active Xbp-1, BiP/GRP78, GADD153/CHOP, JNK, and c-Jun, followed by caspase-dependent apoptosis. These cells also respond to ER stress by increased expression of GADD $45 \alpha$, a p53-regulated and DNA damage-inducible protein, which is not a part of UPR but has recently been demonstrated to play a role in a cell cycle checkpoint arresting cells at G2/M phase in response to DNA damage [153]. In exocrine pancreas cells, the fluoride-induced ER stress was shown to increase eIF2 $\alpha$ phosphorylation and CHOP expression, but did not affect GRP78, while spliced XBP-1 expression was decreased, indicating that ER stress under influence of fluoride can also activate another type of cell death, autophagy, without UPR [154].

\section{Conclusions}

In this work, we have focused on the intracellular molecular mechanisms proven to be responsible for cytotoxicity and development of cell death induced by inorganic fluoride. During the last decades, fluoride was established to be a potent inducer of cell death in many cultured cell types and experimental animal models, and a significant progress has been made towards understanding the molecular mechanisms underlying fluoride toxicity. It activates virtually all known intracellular signaling pathways including $G$ protein-dependent pathways, caspases, and mitochondria- and death receptors-linked mechanisms, as well as triggers a range of metabolic and transcription alterations, including the expression of several apoptosis-related genes, ultimately leading to cell death. However, knowledge of the intracellular pathways involved in the development of fluoride-induced cell death is still incomplete, probably due to complexity and diversity of the molecular events underlying fluoride toxicity. Although many proteins involved in the development of fluoride-induced apoptosis have been identified to date, most of the targets and the exact intracellular spatial and time-dependent chains of events are still unknown, the direct relationship between described mechanisms and fluorideinduced cell death has not always been established, and existing data are sometimes incomplete and controversial. The future intensive investigations are required to identify the whole cascade of events involved in the development of fluoride-induced cytotoxicity and cell death, as well as the mechanisms of their regulation.

\section{Acknowledgment}

The work was financially supported by the Russian Fund of Fundamental Investigations (project 09-04-01679a).

\section{References}

[1] R. Fuge, "Sources of halogens in the environment, influences on human and animal health," Environmental Geochemistry and Health, vol. 10, no. 2, pp. 51-61, 1988.

[2] R. B. Symonds, W. I. Rose, and M. H. Reed, "Contribution of Cl- and F-bearing gases to the atmosphere by volcanoes," Nature, vol. 334, no. 6181, pp. 415-418, 1988.

[3] WHO (World Health Organization), K. Bailey, J. Chilton et al., Eds., Fluoride in Drinking Water, WHO Press, Geneva, Switzerland, 2006.

[4] Environmental Health Criteria (EHC) 227, Fluorides, World Health Organization, Geneva, Switzerland, 2002.

[5] F. M. Fordyce, K. Vrana, E. Zhovinsky et al., "A health risk assessment for fluoride in Central Europe," Environmental Geochemistry and Health, vol. 29, no. 2, pp. 83-102, 2007.

[6] M. H. Wong, K. F. Fung, and H. P. Carr, "Aluminium and fluoride contents of tea, with emphasis on brick tea and their health implications," Toxicology Letters, vol. 137, no. 1-2, pp. 111-120, 2003.

[7] G. Pizzo, M. R. Piscopo, I. Pizzo, and G. Giuliana, "Community water fluoridation and caries prevention: a critical review," Clinical Oral Investigations, vol. 11, no. 3, pp. 189193, 2007.

[8] V. Dhar and M. Bhatnagar, "Physiology and toxicity of fluoride," Indian Journal of Dental Research, vol. 20, no. 3, pp. 350-355, 2009.

[9] T. Aoba and O. Fejerskov, "Dental fluorosis: chemistry and biology," Critical Reviews in Oral Biology and Medicine, vol. 13, no. 2, pp. 155-170, 2002.

[10] Q. Q. Tang, J. Du, H. H. Ma, S. J. Jiang, and X. J. Zhou, "Fluoride and children's intelligence: a meta-analysis," Biological Trace Element Research, vol. 126, no. 1-3, pp. 115120, 2008.

[11] A. L. J. J. Bronckers, D. M. Lyaruu, and P. K. Denbesten, "The impact of fluoride on ameloblasts and the mechanisms 
of enamel fluorosis," Journal of Dental Research, vol. 88, pp. 877-893, 2009.

[12] D. Raja Reddy, "Neurology of endemic skeletal fluorosis," Neurology India, vol. 57, no. 1, pp. 7-12, 2009.

[13] K. A. V. R. Krishnamachari, "Skeletal fluorosis in humans: a review of recent progress in the understanding of the disease," Progress in Food and Nutrition Science, vol. 10, no. 3-4, pp. 279-314, 1986.

[14] G. M. Whitford, "Intake and metabolism of fluoride," Advances in Dental Research, vol. 8, no. 1, pp. 5-14, 1994.

[15] J. Gutknecht and A. Walter, "Hydrofluoric and nitric acid transport through lipid bilayer membranes," Biochimica et Biophysica Acta, vol. 644, no. 1, pp. 153-156, 1981.

[16] R. C. Baselt, Disposition of Toxic Drugs and Chemicals in Man, Biomedical Publications, Foster City, Calif, USA, 7th edition, 2004.

[17] O. Barbier, L. Arreola-Mendoza, and L. M. Del Razo, "Molecular mechanisms of fluoride toxicity," Chemico-Biological Interactions, vol. 188, no. 2, pp. 319-333, 2010.

[18] K. Kubota, D. H. Lee, M. Tsuchiya et al., "Fluoride induces endoplasmic reticulum stress in ameloblasts responsible for dental enamel formation," The Journal of Biological Chemistry, vol. 280, no. 24, pp. 23194-23202, 2005.

[19] Q. Yan, Y. Zhang, W. Li, and P. K. DenBesten, "Micromolar fluoride alters ameloblast lineage cells in vitro," Journal of Dental Research, vol. 86, no. 4, pp. 336-340, 2007.

[20] L. F. Jacinto-Alemán, J. C. Hernández-Guerrero, C. TrejoSolís, M. D. Jiménez-Farfán, and A. M. Fernández-Presas, "In vitro effect of sodium fluoride on antioxidative enzymes and apoptosis during murine odontogenesis," Journal of Oral Pathology and Medicine, vol. 39, no. 9, pp. 709-714, 2010.

[21] H. Karube, G. Nishitai, K. Inageda, H. Kurosu, and M. Matsuoka, "NaF activates MAPKs and induces apoptosis in odontoblast-like cells," Journal of Dental Research, vol. 88, no. 5, pp. 461-465, 2009.

[22] W. J. Qu, D. B. Zhong, P. F. Wu, J. F. Wang, and B. Han, "Sodium fluoride modulates caprine osteoblast proliferation and differentiation," Journal of Bone and Mineral Metabolism, vol. 26, no. 4, pp. 328-334, 2008.

[23] X. Yan, C. Feng, Q. Chen et al., "Effects of sodium fluoride treatment in vitro on cell proliferation, apoptosis and caspase-3 and caspase- 9 mRNA expression by neonatal rat osteoblasts," Archives of Toxicology, vol. 83, no. 5, pp. 451458, 2009.

[24] S. Yang, Z. Wang, C. Farquharson et al., "Sodium fluoride induces apoptosis and alters bcl-2 family protein expression in MC3T3-E1 osteoblastic cells," Biochemical and Biophysical Research Communications, vol. 410, no. 4, pp. 910-915, 2011.

[25] E. V. Thrane, M. Refsnes, G. H. Thoresen, M. Låg, and P. E. Schwarze, "Fluoride-induced apoptosis in epithelial lung cells involves activation of MAP kinases p38 and possibly JNK," Toxicological Sciences, vol. 61, no. 1, pp. 83-91, 2001.

[26] M. Refsnes, P. E. Schwarze, J. A. Holme, and M. Låg, "Fluoride-induced apoptosis in human epithelial lung cells (A549 cells): role of different G protein-linked signal systems," Human and Experimental Toxicology, vol. 22, no. 3, pp. 111-123, 2003.

[27] H. Xu, X. Q. Jin, L. Jing, and G. S. Li, "Effect of sodium fluoride on the expression of Bcl-2 family and osteopontin in rat renal tubular cells," Biological Trace Element Research, vol. 109, no. 1, pp. 55-60, 2006.

[28] C. Bai, T. Chen, Y. Cui, T. Gong, X. Peng, and H. M. Cui, "Effect of high fluorine on the cell cycle and apoptosis of renal cells in chickens," Biological Trace Element Research, vol. 138, no. 1-3, pp. 173-180, 2010.
[29] A. G. Wang, T. Xia, Q. L. Chu et al., "Effects of fluoride on lipid peroxidation, DNA damage and apoptosis in human embryo hepatocytes," Biomedical and Environmental Sciences, vol. 17, no. 2, pp. 217-222, 2004.

[30] X. A. Zhan, M. Wang, Z. R. Xu, W. F. Li, and J. X. Li, "Evaluation of caspase-dependent apoptosis during fluorideinduced liver lesion in pigs," Archives of Toxicology, vol. 80, no. 2, pp. 74-80, 2006.

[31] L. F. He and J. G. Chen, "DNA damage, apoptosis and cell cycle changes induced by fluoride in rat oral mucosal cells and hepatocytes," World Journal of Gastroenterology, vol. 12, no. 7, pp. 1144-1148, 2006.

[32] Y. Ge, H. Ning, C. Feng et al., "Apoptosis in brain cells of offspring rats exposed to high fluoride and low iodine," Fluoride, vol. 39, no. 3, pp. 173-178, 2006.

[33] M. Zhang, A. Wang, T. Xia, and P. He, "Effects of fluoride on DNA damage, S-phase cell-cycle arrest and the expression of NF- $\kappa \mathrm{B}$ in primary cultured rat hippocampal neurons," Toxicology Letters, vol. 179, no. 1, pp. 1-5, 2008.

[34] Y.-J. Liu, Z.-Z. Guan, Q. Gao, and J.-J. Pei, "Increased level of apoptosis in rat brains and SH-SY5Y cells exposed to excessive fluoride - a mechanism connected with activating JNK phosphorylation," Toxicology Letters, vol. 204, no. 2-3, pp. 183-189, 2011.

[35] A. C. Loweth, G. T. Williams, J. H. B. Scarpello, and N. G. Morgan, "Heterotrimeric G-proteins are implicated in the regulation of apoptosis in pancreatic $\beta$-cells," Experimental Cell Research, vol. 229, no. 1, pp. 69-76, 1996.

[36] J. Elliott, J. H. B. Scarpello, and N. G. Morgan, "Effects of tyrosine kinase inhibitors on cell death induced by sodium fluoride and pertussis toxin in the pancreatic $\beta$-cell line, RINm5F," British Journal of Pharmacology, vol. 132, no. 1, pp. 119-126, 2001.

[37] H. Wang, B. Zhou, J. Cao, X. Gu, C. Cao, and J. Wang, "Effects of dietary protein and calcium on thymus apoptosis induced by fluoride in female rats (wistar rats)," Environmental Toxicology, vol. 24, no. 3, pp. 218-224, 2009.

[38] M. Guney, B. Oral, G. Take, S. G. Giray, and T. Mungan, "Effect of fluoride intoxication on endometrial apoptosis and lipid peroxidation in rats: role of vitamins E and C," Toxicology, vol. 231, no. 2-3, pp. 215-223, 2007.

[39] M. Guney, B. Oral, H. Demirin, N. Karahan, T. Mungan, and N. Delibas, "Protective effects of vitamins C and E against endometrial damage and oxidative stress in fluoride intoxication," Clinical and Experimental Pharmacology and Physiology, vol. 34, no. 5-6, pp. 467-474, 2007.

[40] A. Machalinska, A. Machoy-Mokrzynska, W. Marlicz, I. Stecewicz, and B. Machalinski, "NaF- induced apoptosis in human bone marrow and cord blood CD34 positive cells," Fluoride, vol. 34, no. 4, pp. 258-263, 2001.

[41] Z. H. Wang, X. L. Li, Z. Q. Yang, and M. Xu, "Fluorineinduced apoptosis and lipid peroxidation in human hair follicles in vitro," Biological Trace Element Research, vol. 137, no. 3, pp. 280-288, 2010.

[42] S. Chouhan and S. J. S. Flora, "Effects of fluoride on the tissue oxidative stress and apoptosis in rats: biochemical assays supported by IR spectroscopy data," Toxicology, vol. 254, no. 1-2, pp. 61-67, 2008.

[43] S. Chouhan, V. Lomash, and S. J. S. Flora, "Fluorideinduced changes in haem biosynthesis pathway, neurological variables and tissue histopathology of rats," Journal of Applied Toxicology, vol. 30, no. 1, pp. 63-73, 2010.

[44] N. I. Agalakova and G. P. Gusev, "Fluoride-induced death of rat erythrocytes in vitro," Toxicology in Vitro, vol. 25, no. 8, pp. 1609-1618, 2011. 
[45] C. D. Anuradha, S. Kanno, and S. Hirano, "Oxidative damage to mitochondria is a preliminary step to caspase-3 activation in fluoride-induced apoptosis in HL-60 cells," Free Radical Biology and Medicine, vol. 31, no. 3, pp. 367-373, 2001.

[46] J. S. Song, H. Y. Lee, E. Lee, H. J. Hwang, and J. H. Kim, "Cytotoxicity and apoptosis induction of sodium fluoride in human promyelocytic leukemia (HL-60) cells," Environmental Toxicology and Pharmacology, vol. 11, no. 2, pp. 8591, 2002.

[47] S. Otsuki, S. R. M. Morshed, S. A. Chowdhury et al., "Possible link between glycolysis and apoptosis induced by sodium fluoride," Journal of Dental Research, vol. 84, no. 10, pp. 919923, 2005.

[48] A. H. Wyllie, "'where, o death, is thy sting?" A brief review of apoptosis biology," Molecular Neurobiology, vol. 42, no. 1, pp. $4-9,2010$.

[49] M. S. Ola, M. Nawaz, and H. Ahsan, "Role of Bcl-2 family proteins and caspases in the regulation of apoptosis," Molecular and Cellular Biochemistry, vol. 351, pp. 41-58, 2011.

[50] E. F. Mason and J. C. Rathmell, "Cell metabolism: an essential link between cell growth and apoptosis," Biochimica et Biophysica Acta, vol. 1813, no. 4, pp. 645-654, 2011.

[51] L. Li, "The biochemistry and physiology of metallic fluoride: action, mechanism, and implications," Critical Reviews in Oral Biology and Medicine, vol. 14, no. 2, pp. 100-114, 2003.

[52] P. C. Sternweis and A. G. Gilman, "Aluminum: a requirement for activation of the regulatory component of adenylate cyclase by fluoride," Proceedings of the National Academy of Sciences of the United States of America, vol. 79, no. 16 I, pp. 4888-4891, 1982.

[53] J. Bigay, P. Deterre, C. Pfister, and M. Chabre, "Fluoride complexes of aluminium or beryllium act on G-proteins as reversibly bound analogues of the gamma phosphate of GTP," The EMBO Journal, vol. 6, no. 10, pp. 2907-2913, 1987.

[54] T. Higashijima, K. M. Ferguson, P. C. Sternweis, E. M. Ross, M. D. Smigel, and A. G. Gilman, "The effect of activating ligands on the intrinsic fluorescence of guanine nucleotidebinding regulatory proteins," The Journal of Biological Chemistry, vol. 262, no. 2, pp. 752-756, 1987.

[55] R. Mittal, M. R. Ahmadian, R. S. Goody, and A. Wittinghofer, "Formation of a transition-state analog of the Ras GTPase reaction by Ras.Gdp, tetrafluoroaluminate, and GTPaseactivating proteins," Science, vol. 273, no. 5271, pp. 115-117, 1996.

[56] A. Wittinghofer, "Signal transduction via Ras," Biological Chemistry, vol. 379, no. 8-9, pp. 933-937, 1998.

[57] P. F. Blackmore, S. B. Bocckino, L. E. Waynick, and J. H. Exton, "Role of a guanine nucleotide-binding regulatory protein in the hydrolysis of hepatocyte phosphatidylinositol 4,5-bisphosphate by calcium-mobilizing hormones and the control of cell calcium," The Journal of Biological Chemistry, vol. 260, no. 27, pp. 14477-14483, 1985.

[58] J. Elliott, J. H. B. Scarpello, and N. G. Morgan, "Differential effects of genistein on apoptosis induced by fluoride and pertussis toxin in human and rat pancreatic islets and RINm5F cells," Journal of Endocrinology, vol. 172, no. 1, pp. 137-143, 2002.

[59] J. H. Dominguez, J. G.N. Garcia, J. K. Rothrock, D. English, and C. Mann, "Fluoride mobilizes intracellular calcium and promotes $\mathrm{Ca}^{2+}$ influx in rat proximal tubules," American Journal of Physiology, vol. 261, no. 2, pp. F318-F327, 1991.

[60] J. G. Garcia, J. Dominguez, and D. English, "Sodium fluoride induces phosphoinositide hydrolysis, $\mathrm{Ca}^{2+}$ mobilization, and prostacyclin synthesis in cultured human endothelium: further evidence for regulation by a pertussis toxin-insensitive guanine nucleotide-binding protein," American Journal of Respiratory Cell and Molecular Biology, vol. 5, no. 2, pp. 113124, 1991.

[61] M. Šuša, G. J. R. Standke, M. Jeschke, and D. Rohner, "Fluoroaluminate induces pertussis toxin-sensitive protein phosphorylation: differences in MC3T3-E1 osteoblastic and NIH3T3 fibroblastic cells," Biochemical and Biophysical Research Communications, vol. 235, no. 3, pp. 680-684, 1997.

[62] M. Susa, "Heterotrimeric G proteins as fluoride targets in bone (review)," International Journal of Molecular Medicine, vol. 3, no. 2, pp. 115-126, 1999.

[63] P. Wang, A. D. Verin, A. Birukova, L. I. Gilbert-McClain, K. Jacobs, and J. G. N. Garcia, "Mechanisms of sodium fluorideinduced endothelial cell barrier dysfunction: role of MLC phosphorylation," American Journal of Physiology, vol. 281, no. 6, pp. L1472-L1483, 2001.

[64] N. V. Bogatcheva, P. Wang, A. A. Birukova, A. D. Verin, and J. G. N. Garcia, "Mechanism of fluoride-induced MAP kinase activation in pulmonary artery endothelial cells," American Journal of Physiology, vol. 290, no. 6, pp. L1139-L1145, 2006.

[65] M. Refsnes, H. Kersten, P. E. Schwarze, and M. Låg, "Involvement of protein kinase $\mathrm{C}$ in fluoride-induced apoptosis in different types of lung cells," Annals of the New York Academy of Sciences, vol. 973, pp. 218-220, 2002.

[66] J. G. Garcia, J. Stasek, V. Natarajan, C. E. Patterson, and J. Dominguez, "Role of protein kinase $\mathrm{C}$ in the regulation of prostaglandin synthesis in human endothelium," American Journal of Respiratory Cell and Molecular Biology, vol. 6, no. 3, pp. 315-325, 1992.

[67] M. E. Reyland and A. P. Bradford, "PKC and the control of apoptosis, Protein kinase C in cancer signaling and therapy," in Current Cancer Research, M. G. Kazanietz, Ed., vol. 2, pp. 189-222, 2010.

[68] G. E. N. Kass and S. Orrenius, "Calcium signaling and cytotoxicity," Environmental Health Perspectives, vol. 107, no. 1, pp. 25-35, 1999.

[69] M. J. Berridge, P. Lipp, and M. D. Bootman, “The versatility and universality of calcium signalling," Nature Reviews Molecular Cell Biology, vol. 1, no. 1, pp. 11-21, 2000.

[70] C. C. Cummings and M. E. McIvor, "Fluoride-induced hyperkalemia: the role of $\mathrm{Ca}^{2+}$-dependent $\mathrm{K}^{+}$channels," American Journal of Emergency Medicine, vol. 6, no. 1, pp. 13, 1988.

[71] J. E. Zerwekh, A. C. Morris, P. K. Padalino, F. Gottschalk, and C. Y. C. Pak, "Fluoride rapidly and transiently raises intracellular calcium in human osteoblasts," Journal of Bone and Mineral Research, vol. 5, no. 1, pp. S131-S136, 1990.

[72] Z. Xu, B. Xu, T. Xia et al., "Relationship between intracellular $\mathrm{Ca}^{2+}$ and ROS during fluoride-induced injury in SH-SY5Y cells," Environmental Toxicology. In press.

[73] H. Murao, N. Sakagami, T. Iguchi, T. Murakami, and Y. Suketa, "Sodium fluoride increases intracellular calcium in rat renal epithelial cell line NRK-52E," Biological and Pharmaceutical Bulletin, vol. 23, no. 5, pp. 581-584, 2000.

[74] A. Kagaya, Y. Uchitomi, A. Kugaya et al., "Differential regulation of intracellular signaling systems by sodium fluoride in rat glioma cells," Journal of Neurochemistry, vol. 66, no. 4, pp. 1483-1488, 1996.

[75] H. Matsui, M. Morimoto, K. Horimoto, and Y. Nishimura, "Some characteristics of fluoride-induced cell death in rat thymocytes: cytotoxicity of sodium fluoride," Toxicology in Vitro, vol. 21, no. 6, pp. 1113-1120, 2007. 
[76] H. Xu, Y. L. Zhou, J. M. Zhang, H. Liu, L. Jing, and G. S. Li, "Effects of fluoride on the intracellular free $\mathrm{Ca}^{2+}$ and $\mathrm{Ca}^{2+}$ ATPase of kidney," Biological Trace Element Research, vol. 116, no. 3, pp. 279-287, 2007.

[77] Z. Sun, R. Niu, K. Su et al., "Effects of sodium fluoride on hyperactivation and $\mathrm{Ca}^{2+}$ signaling pathway in sperm from mice: an in vivo study," Archives of Toxicology, vol. 84, no. 5, pp. 353-361, 2010.

[78] M. Los, S. Maddika, B. Erb, and K. Schulze-Osthoff, "Switching Akt: from survival signaling to deadly response," BioEssays, vol. 35, pp. 492-495, 2009.

[79] N. Wettschureck and S. Offermanns, "Rho/Rho-kinase mediated signaling in physiology and pathophysiology," Journal of Molecular Medicine, vol. 80, no. 10, pp. 629-638, 2002.

[80] E. Yang, S. B. Jeon, I. Baek, M. J. Song, Y. R. Yoon, and I. K. Kim, "Fluoride induces vascular contraction through activation of RhoA/Rho kinase pathway in isolated rat aortas," Environmental Toxicology and Pharmacology, vol. 29, no. 3, pp. 290-296, 2010.

[81] M. A. Lemmon and J. Schlessinger, "Cell signaling by receptor tyrosine kinases," Cell, vol. 141, no. 7, pp. 1117-1134, 2010.

[82] F. Vinals, X. Testar, M. Palacin, and A. Zorzano, "Inhibitory effect of fluoride on insulin receptor autophosphorylation and tyrosine kinase activity," Biochemical Journal, vol. 291, no. 2, pp. 615-622, 1993.

[83] A. Plotnikov, E. Zehorai, S. Procaccia, and R. Seger, "The MAPK cascades: signaling components, nuclear roles and mechanisms of nuclear translocation," Biochimica et Biophysica Acta, vol. 1813, pp. 1619-1633, 2011.

[84] L. W. Wu, H. K. Yoon, D. J. Baylink, L. M. Graves, and K. H. W. Lau, "Fluoride at mitogenic doses induces a sustained activation of $\mathrm{p} 44$ (mapk), but not p42(mapk), in human TE85 osteosarcoma cells," Journal of Clinical Endocrinology and Metabolism, vol. 82, no. 4, pp. 1126-1135, 1997.

[85] Y. Zhang, W. Li, H. S. Chi, J. Chen, and P. K. DenBesten, "JNK/c-Jun signaling pathway mediates the fluoride-induced down-regulation of MMP-20 in vitro," Matrix Biology, vol. 26, no. 8, pp. 633-641, 2007.

[86] Q. Chen, Z. Wang, Y. Xiong, X. Zou, and Z. Liu, “Comparative study of p38 MAPK signal transduction pathway of peripheral blood mononuclear cells from patients with coal-combustion-type fluorosis with and without high hair selenium levels," International Journal of Hygiene and Environmental Health, vol. 213, no. 5, pp. 381-386, 2010.

[87] G. Gloire, E. Charlier, and J. Piette, "Regulation of CD95/ APO-1/Fas-induced apoptosis by protein phosphatases," Biochemical Pharmacology, vol. 76, no. 11, pp. 1451-1458, 2008.

[88] M. R. Junttila, S. P. Li, and J. Westermarck, "Phosphatasemediated crosstalk between MAPK signaling pathways in the regulation of cell survival," The FASEB Journal, vol. 22, no. 4, pp. 954-965, 2008.

[89] E. Shacter-Noiman and P. B. Chock, "Properties of a $\mathrm{Mr}=38,000$ phosphoprotein phosphatase. Modulation by divalent cations, ATP, and fluoride," The Journal of Biological Chemistry, vol. 258, no. 7, pp. 4214-4219, 1983.

[90] R. Franco, C. D. Bortner, and J. A. Cidlowski, "Potential roles of electrogenic ion transport and plasma membrane depolarization in apoptosis," Journal of Membrane Biology, vol. 209, no. 1, pp. 43-58, 2006.

[91] T. I. Ivanova, N. I. Agalakova, and G. P. Gusev, "Activation of sodium transport in rat erythrocytes by inhibition of protein phosphatases 1 and 2A," Comparative Biochemistry and Physiology B, vol. 145, no. 1, pp. 60-67, 2006.
[92] N. I. Agalakova and G. P. Gusev, "Diverse effects of fluoride on $\mathrm{Na}^{+}$and $\mathrm{K}^{+}$transport across the rat erythrocyte membrane," Fluoride, vol. 41, pp. 28-39, 2008.

[93] C. Lytle, "Activation of the avian erythrocyte $\mathrm{Na}-\mathrm{K}-\mathrm{Cl}$ cotransport protein by cell shrinkage, cAMP, fluoride, and calyculin-A involves phosphorylation at common sites," The Journal of Biological Chemistry, vol. 272, no. 24, pp. 1506915077, 1997.

[94] G. P. Gusev and N. I. Agalakova, "Regulation of K-Cl cotransport in erythrocytes of frog Rana temporaria by commonly used protein kinase and protein phosphatase inhibitors," Journal of Comparative Physiology B, vol. 180, no. 3, pp. 385-391, 2010.

[95] R. Franco and J. A. Cidlowski, "Apoptosis and glutathione: beyond an antioxidant," Cell Death and Differentiation, vol. 16, no. 10, pp. 1303-1314, 2009.

[96] D. Chlubek, "Fluoride and oxidative stress," Fluoride, vol. 36, no. 4, pp. 217-228, 2003.

[97] G. B. Reddy, A. L. Khandare, P. Y. Reddy, G. S. Rao, N. Balakrishna, and I. Srivalli, "Antioxidant defense system and lipid peroxidation in patients with skeletal fluorosis and in fluoride-intoxicated rabbits," Toxicological Sciences, vol. 72, no. 2, pp. 363-368, 2003.

[98] J. H. Lee, J. Y. Jung, Y. J. Jeong et al., "Involvement of both mitochondrial- and death receptor-dependent apoptotic pathways regulated by Bcl-2 family in sodium fluorideinduced apoptosis of the human gingival fibroblasts," Toxicology, vol. 243, no. 3, pp. 340-347, 2008.

[99] J. A. Izquierdo-Vega, M. Sánchez-Gutiérrez, and L. M. Del Razo, "Decreased in vitro fertility in male rats exposed to fluoride-induced oxidative stress damage and mitochondrial transmembrane potential loss," Toxicology and Applied Pharmacology, vol. 230, no. 3, pp. 352-357, 2008.

[100] J. A. Izquierdo-Vega, M. Sánchez-Gutiérrez, and L. M. del Razo, "NADPH oxidase participates in the oxidative damage caused by fluoride in rat spermatozoa. Protective role of $\alpha$ tocopherol," Journal of Applied Toxicology, vol. 31, no. 6, pp. 579-588, 2011.

[101] E. A. García-Montalvo, H. Reyes-Pérez, and L. M. Del Razo, "Fluoride exposure impairs glucose tolerance via decreased insulin expression and oxidative stress," Toxicology, vol. 263, no. 2-3, pp. 75-83, 2009.

[102] Y. Y. Wang, B. L. Zhao, X. J. Li, Z. Su, and W. J. Xi, "Spin trapping technique studies on active oxygen radicals from human polymorphonuclear leukocytes during fluoridestimulated respiratory burst," Fluoride, vol. 30, no. 1, pp. 5$15,1997$.

[103] I. Gutowska, I. Baranowska-Bosiacka, M. Baśkiewicz et al., "Fluoride as a pro-inflammatory factor and inhibitor of ATP bioavailability in differentiated human THP1 monocytic cells,” Toxicology Letters, vol. 196, no. 2, pp. 74-79, 2010.

[104] J. Ghosh, J. Das, P. Manna, and P. C. Sil, "Cytoprotective effect of arjunolic acid in response to sodium fluoride mediated oxidative stress and cell death via necrotic pathway," Toxicology in Vitro, vol. 22, no. 8, pp. 1918-1926, 2008.

[105] Z. Sun, R. Niu, B. Wang et al., "Fluoride-induced apoptosis and gene expression profiling in mice sperm in vivo," Archives of Toxicology, vol. 85, pp. 1441-1452, 2011.

[106] Y. M. Shivarajashankara, A. R. Shivashankara, B. P. Gopalakrishna, and S. H. Rao, "Oxidative stress in children with endemic skeletal fluorosis," Fluoride, vol. 34, pp. 108-113, 2001.

[107] P. Kalyanalakshmi, M. Vijayabhaskar, and M. Dhananjaya Naidu, "Lipid peroxidation and antioxidant enzyme status of 
adult males with skeletal fluorosis in Andhra Pradesh, India," Fluoride, vol. 40, no. 1, pp. 42-45, 2007.

[108] Y. M. Shivarajashankara, A. R. Shivashankara, P. Gopalakrishna Bhat, and S. Hanumanth Rao, "Effect of fluoride intoxication on lipid peroxidation and antioxidant systems in rats," Fluoride, vol. 34, no. 2, pp. 108-113, 2001.

[109] Y. M. Shivarajashankara, A. R. Shivashankara, P. Gopalakrishna Bhat, and S. Hanumanth Rao, "Lipid peroxidation and antioxidant systems in the blood of young rats subjected to chronic fluoride toxicity," Indian Journal of Experimental Biology, vol. 41, no. 8, pp. 857-860, 2003.

[110] I. Inkielewicz and J. Krechniak, "Fluoride effects on glutathione peroxidase and lipid peroxidation in rats," Fluoride, vol. 37, no. 1, pp. 7-12, 2004.

[111] I. Błaszczyk, E. Grucka-Mamczar, S. Kasperczyk, and E. Birkner, "Influence of methionine upon the concentration of malondialdehyde in the tissues and blood of rats exposed to sodium fluoride," Biological Trace Element Research, vol. 129, no. 1-3, pp. 229-238, 2009.

[112] E. Karaoz, M. Oncu, K. Gulle et al., "Effect of chronic fluorosis on lipid peroxidation and histology of kidney tissues in first- and second-generation rats," Biological Trace Element Research, vol. 102, no. 1-3, pp. 199-208, 2004.

[113] H. Xu, C. H. Wang, Z. T. Zhao, W. B. Zhang, and G. S. Li, "Role of oxidative stress in osteoblasts exposed to sodium fluoride," Biological Trace Element Research, vol. 123, no. 1-3, pp. 109-115, 2008.

[114] J. Jeji, R. Sharma, S. S. Jolly, and S. Pamnani, "Implication of glutathione in endemic fluorosis," Fluoride, vol. 18, no. 2, pp. 117-119, 1985.

[115] J. Li and S. Ca, "Recent studies on endemic fluorosis in China," Fluoride, vol. 27, pp. 125-128, 1994.

[116] M. Sinha, P. Manna, and P. C. Sil, "A $43 \mathrm{kD}$ protein from the herb, Cajanus indicus L., protects against fluoride induced oxidative stress in mice erythrocytes," Pathophysiology, vol. 14, no. 1, pp. 47-54, 2007.

[117] D. Shanthakumari, S. Srinivasalu, and S. Subramanian, "Effect of fluoride intoxication on lipidperoxidation and antioxidant status in experimental rats," Toxicology, vol. 204, no. 2-3, pp. 219-228, 2004.

[118] H. A. Hassan and M. I. Yousef, "Mitigating effects of antioxidant properties of black berry juice on sodium fluoride induced hepatotoxicity and oxidative stress in rats," Food and Chemical Toxicology, vol. 47, no. 9, pp. 2332-2337, 2009.

[119] M. L. Vani and K. P. Reddy, "Effects of fluoride accumulation on some enzymes of brain and gastrocnemius muscle of mice," Fluoride, vol. 33, no. 1, pp. 17-26, 2000.

[120] G. Liu, C. Chai, and L. Cui, "Fluoride causing abnormally elevated serum nitric oxide levels in chicks," Environmental Toxicology and Pharmacology, vol. 13, no. 3, pp. 199-204, 2003.

[121] J. J. Lemasters, "Dying a thousand deaths: redundant pathways from different organelles to apoptosis and necrosis," Gastroenterology, vol. 129, no. 1, pp. 351-360, 2005.

[122] J. Qin, G. Chai, J. M. Brewer, L. L. Lovelace, and L. Lebioda, "Fluoride inhibition of enolase: crystal structure and thermodynamics," Biochemistry, vol. 45, no. 3, pp. 793800, 2006.

[123] S. A. Feig, S. B. Shohet, and D. G. Nathan, "Energy metabolism in human erythrocytes. I. Effects of sodium fluoride," Journal of Clinical Investigation, vol. 50, no. 8, pp. 1731-1737, 1971.

[124] J. H. Jeng, C. C. Hsieh, W. H. Lan et al., "Cytotoxicity of sodium fluoride on human oral mucosal fibroblasts and its mechanisms," Cell Biology and Toxicology, vol. 14, no. 6, pp. 383-389, 1998.

[125] M. L. Coleman, E. A. Sahai, M. Yeo, M. Bosch, A. Dewar, and M. F. Olson, "Membrane blebbing during apoptosis results from caspase-mediated activation of ROCK I," Nature Cell Biology, vol. 3, no. 4, pp. 339-345, 2001.

[126] L. P. Wen, J. A. Fahrni, S. Troie, J. L. Guan, K. Orth, and G. D. Rosen, "Cleavage of focal adhesion kinase by caspases during apoptosis," The Journal of Biological Chemistry, vol. 272, no. 41, pp. 26056-26061, 1997.

[127] S. Nagata, "Apoptotic DNA fragmentation," Experimental Cell Research, vol. 256, no. 1, pp. 12-18, 2000.

[128] R. Kim, M. Emi, and K. Tanabe, "Role of mitochondria as the gardens of cell death," Cancer Chemotherapy and Pharmacology, vol. 57, no. 5, pp. 545-553, 2006.

[129] C. D. Anuradha, S. Kanno, and S. Hirano, "Fluoride induces apoptosis by caspase- 3 activation in human leukemia HL-60 cells," Archives of Toxicology, vol. 74, no. 4-5, pp. 226-230, 2000.

[130] B. Xu, Z. Xu, T. Xia et al., "Effects of the Fas/Fas-L pathway on fluoride-induced apoptosis in SH-SY5Y cells," Environmental Toxicology, vol. 26, no. 1, pp. 86-92, 2011.

[131] J. Gutiérrez-Salinas, J. A. Morales-González, E. MadrigalSantillán et al., "Exposure to sodium fluoride produces signs of apoptosis in rat leukocytes," International Journal of Molecular Sciences, vol. 11, no. 9, pp. 3610-3622, 2010.

[132] G. Ren, K. Wang, R. Chang et al., "Simultaneous administration of fluoride and selenite regulates proliferation and apoptosis in murine osteoblast-like MC3T3-E1 cells by altering osteoprotegerin," Biological Trace Element Research, vol. 144, no. 1-3, pp. 1437-1448, 2011.

[133] C.-H. Chien, H. Sakagami, M. Kouhara, A. Sasaki, K. Matsumoto, and H. Kanegae, "Effect of simulated orthodontic forces on flouride-induced cytotoxicity in MC3T3-E1 osteoblast-like cells," In Vivo, vol. 23, no. 2, pp. 259-266, 2009.

[134] A. Burlacu, "Regulation of apoptosis by Bcl-2 family proteins," Journal of Cellular and Molecular Medicine, vol. 7, no. 3, pp. 249-257, 2003.

[135] S. Otsuki, K. Sugiyama, O. Amano, T. Yasui, and H. Sakagami, "Negative regulation of NaF-induced apoptosis by Bad-CAII complex," Toxicology, vol. 287, no. 1-3, pp. 131136, 2011.

[136] C. L. Tsai, J. W. Lin, H. K. Kuo et al., "Induction of apoptosis in rabbit oral mucosa by $1.23 \%$ acidulated phosphate fluoride gel," Archives of Toxicology, vol. 82, no. 2, pp. 81-87, 2008.

[137] W. Sun and J. Yang, "Functional mechanisms for human tumor suppression," Journal of Cancer, vol. 15, pp. 136-140, 2010.

[138] O. D.K. Maddocks and K. H. Vousden, "Metabolic regulation by p53," Journal of Molecular Medicine, vol. 89, no. 3, pp. 237245, 2011.

[139] A. G. Wang, Q. L. Chu, W. H. He et al., "Effects on protein and mRNA expression levels of p53 induced by fluoride in human embryonic hepatocytes," Toxicology Letters, vol. 158, no. 2, pp. 158-163, 2005.

[140] M. Salgado-Bustamante, M. D. Ortiz-Pérez, E. CalderónAranda et al., "Pattern of expression of apoptosis and inflammatory genes in humans exposed to arsenic and/or fluoride," Science of the Total Environment, vol. 408, no. 4, pp. 760-767, 2010.

[141] J. Lu, H. Chen, Q. Xu et al., "Comparative proteomics of kidney samples from puffer fish Takifugu rubripes exposed 
to excessive fluoride: an insight into molecular response to fluorosis," Toxicology Mechanisms and Methods, vol. 20, no. 6, pp. 345-354, 2010.

[142] J. Lu, J. Zheng, H. Liu, J. Li, Q. Xu, and K. Chen, "Proteomics analysis of liver samples from puffer fish Takifugu rubripes exposed to excessive fluoride: an insight into molecular response to fluorosis," Journal of Biochemical and Molecular Toxicology, vol. 24, no. 1, pp. 21-28, 2010.

[143] J. Lu, Q. Xu, J. Zheng, H. Liu, J. Li, and K. Chen, "Comparative proteomics analysis of cardiac muscle samples from pufferfish Takifugu rubripes exposed to excessive fluoride: initial molecular response to fluorosis," Toxicology Mechanisms and Methods, vol. 19, no. 6-7, pp. 468-475, 2009.

[144] H. Okudo, H. Kato, Y. Arakaki, and R. Urade, "Cooperation of ER-60 and BiP in the oxidative refolding of denatured proteins in vitro," The Journal of Biological Chemistry, vol. 138, no. 6, pp. 773-780, 2005.

[145] G. Giancarlo, "SMC3 knockdown triggers genomic instability and p53-dependent apoptosis in human and zebrafish cells," Molecular Cancer, vol. 5, pp. 52-65, 2006.

[146] F. Chen and V. Castranova, "Nuclear factor- $\kappa \mathrm{B}$, an unappreciated tumor suppressor," Cancer Research, vol. 67, no. 23, pp. 11093-11098, 2007.

[147] M. Fu, C. Wang, Z. Li, T. Sakamaki, and R. G. Pestell, "Minireview: cyclin D1: normal and abnormal functions," Endocrinology, vol. 145, no. 12, pp. 5439-5447, 2004.

[148] M. Zhang, A. Wang, W. He et al., "Effects of fluoride on the expression of NCAM, oxidative stress, and apoptosis in primary cultured hippocampal neurons," Toxicology, vol. 236, no. 3, pp. 208-216, 2007.

[149] C. Y. Liu and R. J. Kaufman, "The unfolded protein response," Journal of Cell Science, vol. 116, no. 10, pp. 18611862, 2003.

[150] R. Kim, M. Emi, K. Tanabe, and S. Murakami, "Role of the unfolded protein response in cell death," Apoptosis, vol. 11, no. 1, pp. 5-13, 2006.

[151] R. Sharma, M. Tsuchiya, and J. D. Bartlett, "Flouride induces endoplasmic reticulum stress and inhibits protein synthesis and secretion," Environmental Health Perspectives, vol. 116, no. 9, pp. 1142-1146, 2008.

[152] R. Sharma, M. Tsuchiya, Z. Skobe, B. A. Tannous, and J. D. Bartlett, "The acid test of fluoride: how $\mathrm{pH}$ modulates toxicity," PloS One, vol. 5, no. 5, Article ID e10895, 2010.

[153] S. Jin, T. Tong, W. Fan et al., "GADD45-induced cell cycle G2-M arrest associates with altered subcellular distribution of cyclin B1 and is independent of p38 kinase activity," Oncogene, vol. 21, no. 57, pp. 8696-8704, 2002.

[154] M. Ito, H. Nakagawa, T. Okada, S. Miyazaki, and S. Matsuo, "ER-stress caused by accumulated intracistanal granules activates autophagy through a different signal pathway from unfolded protein response in exocrine pancreas cells of rats exposed to fluoride," Archives of Toxicology, vol. 83, no. 2, pp. 151-159, 2009. 

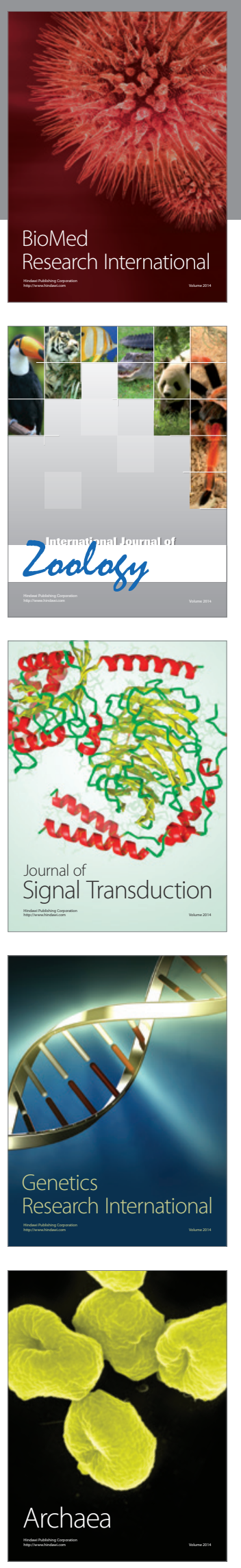
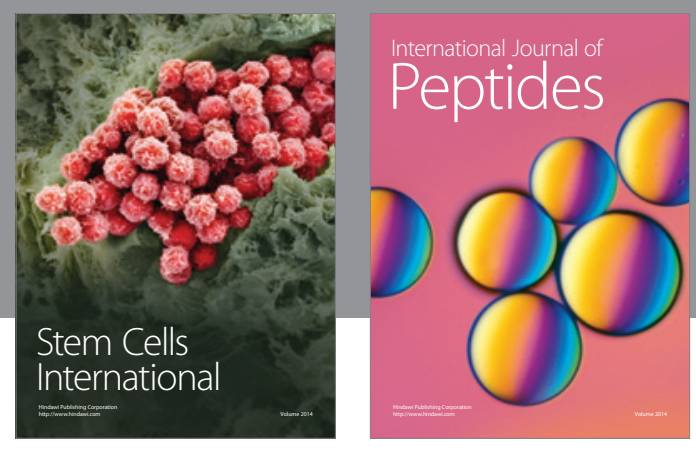

Submit your manuscripts at

http://www.hindawi.com
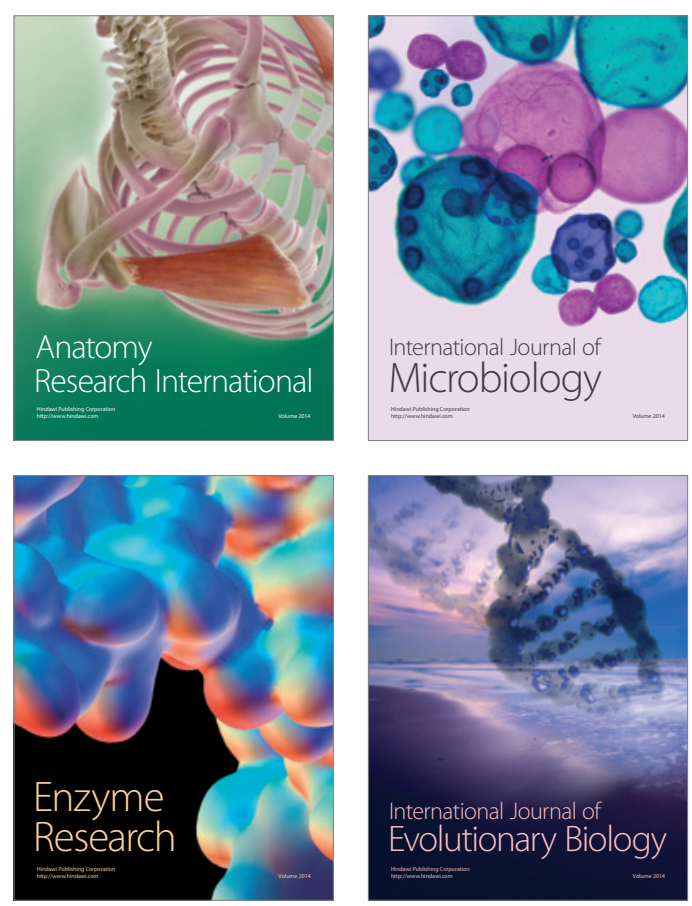
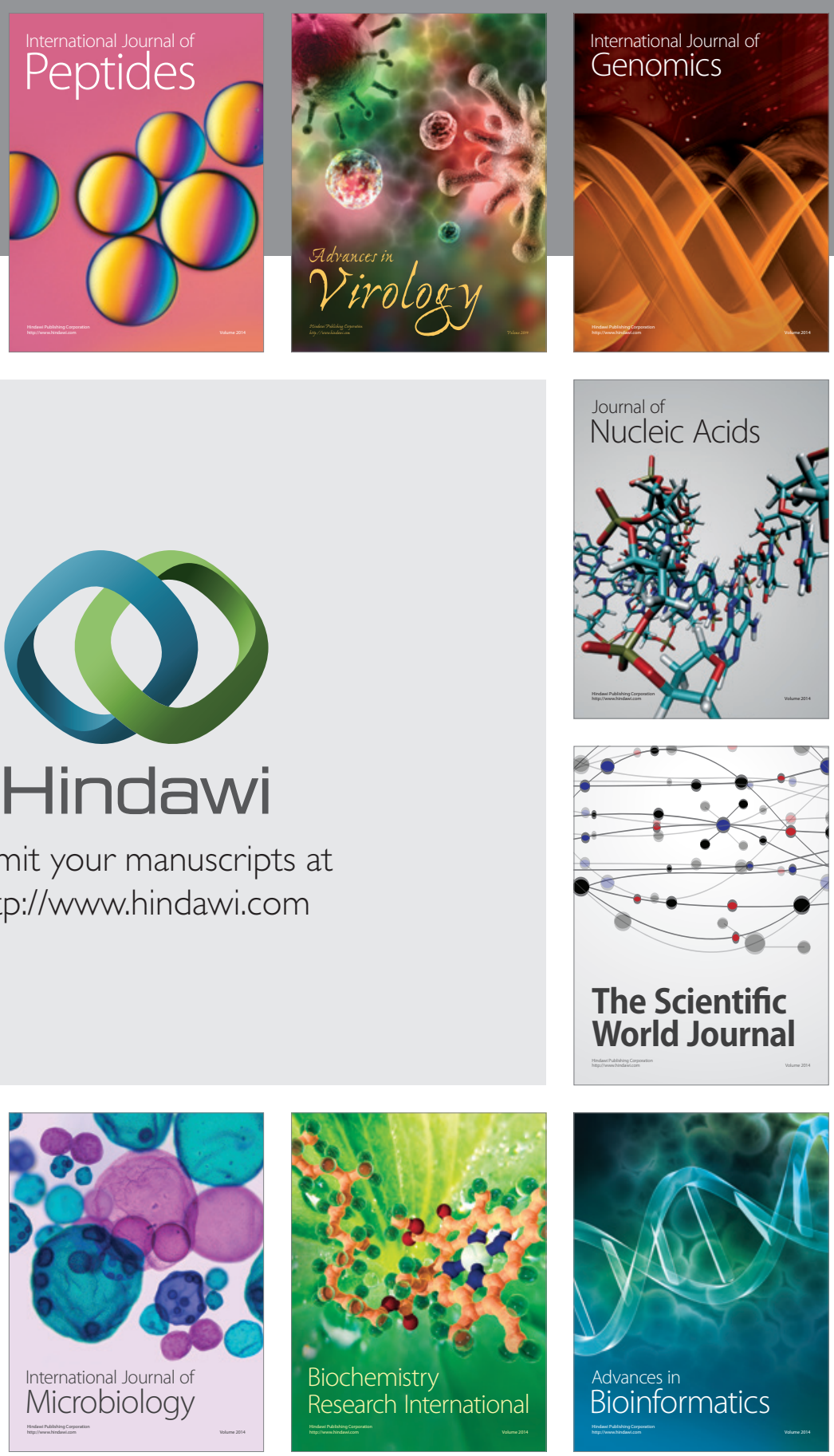

The Scientific World Journal
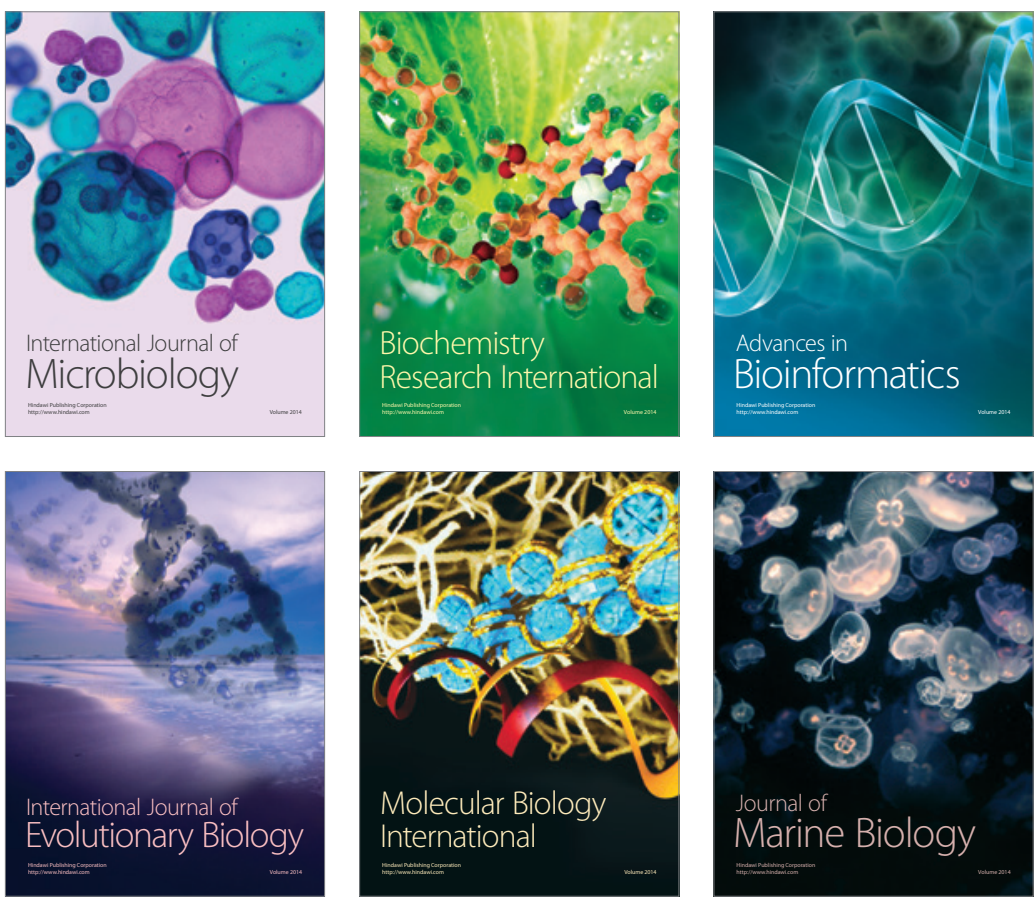